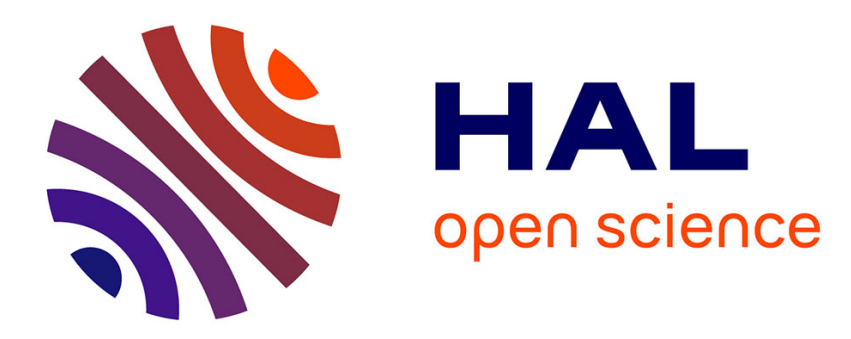

\title{
Le musée de Vat Phu et les collections archéologiques de Champassak
}

Christine Hawixbrock

\section{To cite this version:}

Christine Hawixbrock. Le musée de Vat Phu et les collections archéologiques de Champassak. Bulletin de l'Ecole française d'Extrême-Orient, 2010, $97-98$ (1), pp.271 - 314. 10.3406/befeo.2010.6135 . halshs-02549195

\section{HAL Id: halshs-02549195 https://shs.hal.science/halshs-02549195}

Submitted on 21 Apr 2020

HAL is a multi-disciplinary open access archive for the deposit and dissemination of scientific research documents, whether they are published or not. The documents may come from teaching and research institutions in France or abroad, or from public or private research centers.
L'archive ouverte pluridisciplinaire HAL, est destinée au dépôt et à la diffusion de documents scientifiques de niveau recherche, publiés ou non, émanant des établissements d'enseignement et de recherche français ou étrangers, des laboratoires publics ou privés. 


\section{Le musée de Vat Phu et les collections archéologiques de}

\section{Champassak}

Christine Hawixbrock

\section{Citer ce document / Cite this document :}

Hawixbrock Christine. Le musée de Vat Phu et les collections archéologiques de Champassak. In: Bulletin de I'Ecole française d'Extrême-Orient. Tome 97-98, 2010. pp. 271-314;

doi : https://doi.org/10.3406/befeo.2010.6135

https://www.persee.fr/doc/befeo_0336-1519_2010_num_97_1_6135

Fichier pdf généré le 08/11/2019 


\begin{abstract}
The Vat Phu Museum houses an important collection comprising some 2000 artifacts, 300 of which are exhibited in the site museum built in 2004 near the temple of Vat Phu, a Unesco Word Heritage site since 2001. This article offers, for the first time, an overview of this collection, built up since the 1980's with artifacts collected at archaeological sites, supplemented by recent excavations and surveys carried out by Lao and international teams. The Prince Boun Oum na Champassak art collection is included in the Museum collection, after it entered the Lao national heritage at the end of the 1970's. Lao Buddhist art from the 17th century until the 20th century is well represented; Khmer art, however, makes the major part of the collection, raising the Vat Phu Museum to the highest level of Lao museum collections. These pieces demonstrate the artistic wealth and the historic significance of the area in the formation of the future Khmer state, starting in the 5th century, and the constant attention paid by the Khmer kings to the Vat Phu sanctuary until the 13 th century.
\end{abstract}

\title{
Résumé
}

Le musée de Vat Phu abrite une importante collection de quelque 2000 pièces, dont près de 300 sont exposées depuis 2004 dans un bâtiment construit aux pieds du temple de Vat Phu, inscrit au Patrimoine mondial par l'Unesco en 2001. Cet article donne pour la première fois une vision d'ensemble de ce fonds, constitué à partir des années 1980 par la collecte d'objets sur les sites archéologiques de la région et enrichi des découvertes faites lors des fouilles et prospections plus récentes des équipes laotiennes et internationales ; la collection inclut aussi l' ex-collection particulière du Prince Boun Oum na Champassak, intégrée au patrimoine national lao à la fin des années 1970. Si l'art bouddhique laotien est bien représenté par une série de pièces datant du XVIle au XXe siècle, la part majeure de la collection est dévolue à l'art khmer, contribuant à placer le musée de Vat Phu au premier plan parmi les collections muséales du Laos. Ces pièces illustrent la richesse artistique et l'importance historique de ce territoire dans la construction du futur État khmer à compter du Ve siècle, puis le souci constant des monarques angkoriens d'entretenir le sanctuaire de Vat Phu jusqu'au XIIle siècle. 


\title{
Le musée de Vat Phu et les collections archéologiques de Champassak
}

\author{
Christine HaWIXBROCK *.
}

Les collections archéologiques du musée de Vat Phu proviennent d'une trentaine de sites de la province de Champassak, dont les principaux sont le complexe monumental établi sur la pente occidentale de la montagne Phu Khao et la ville ancienne riveraine du Mékong, supposée être la première capitale de la dynastie khmère du Zhenla. La grande majorité des objets et vestiges conservés appartiennent aux périodes préangkorienne ( $\mathrm{V}^{\mathrm{e}}-\mathrm{VIII} \mathrm{I}^{\mathrm{e}}$ siècle) et angkorienne ( $\mathrm{IX}^{\mathrm{e}}-\mathrm{XIII}^{\mathrm{e}}$ siècle). Des pièces d'art bouddhique laotien plus tardives ( $\mathrm{XVII}^{\mathrm{e}}-\mathrm{XX}^{\mathrm{e}}$ siècle) font également partie des collections, ainsi que les éléments d'un fonds princier devenu patrimoine national.

Riches de quelque 1490 pièces cataloguées (près de 400 objets supplémentaires vont entrer prochainement à l'inventaire), les collections archéologiques réunies à Champassak ne sont pas toutes accessibles au public. Le musée de Vat Phu, ouvert en 2004, expose une sélection de 225 pièces représentatives des différentes périodes historiques (fig. 1 et 2). Le reste est conservé dans une réserve adjacente, ainsi que dans un dépôt de la ville de Champassak. Quelques objets sont exposés dans d'autres musées, notamment ceux de Paksé - chef-lieu de la province - et de Vientiane. Plusieurs inventaires des collections archéologiques de Champassak ont été ébauchés depuis une trentaine d'années. Le recensement systématique des pièces n'a cependant commencé qu'en 2009 ; il s'appuie sur une base de données informatique spécialement conçue pour le projet.

La présente étude est le résultat d'un premier examen des données que nous avons collectées au cours de deux missions mandatées par la Direction du site du patrimoine mondial du Vat Phu-Champassak (DPV), dont les objectifs étaient l'inventaire descriptif des collections et la mise en valeur du musée du site ${ }^{1}$. Ces tâches avaient pour corollaires le réaménagement et le rangement de la réserve du musée, la réorganisation des collections exposées et la formation des cadres locaux du DPV à l'histoire de l'art, aux techniques d'inventaire scientifique et à l'utilisation d'une base documentaire ${ }^{2}$. Le programme de réaménagement des collections exposées a été mené conjointement avec Bertrand Porte (EFEO), responsable de l'atelier des grès au Musée national du Cambodge à Phnom Penh (MNC). M. Sok Soda (MNC), a complété ce programme en 2011 par la formation du personnel de la conservation de Vat Phu à la restauration des pièces en pierre.

* École française d'Extrême-Orient.

1. Ces missions, effectuées d'août à décembre 2009 et en août 2010 , ont été organisées dans le cadre des actions du Fonds de solidarité prioritaire (FSP) pour Vat Phu, projet de coopération franco-laotien mené grâce à l'assistance technique de M. Laurent Delfour, architecte et urbaniste de l'État. Nous remercions ici M. Thongsa Sayavongkhamdy, directeur général du Patrimoine au ministère de l'Information et de la Culture, ainsi que les responsables du DPV, MM. Khankham Kcnboutta ct Bounlap Keokagna, pour le soutien qu'ils ont apporté à ces travaux. Ceux-ci seront finalisés prochainement.

2. Le catalogage informatique prend en compte les données issues des cahiers d'inventaire préexistants, rédigés en laotien. Ces derniers consignent la date d'entrée et le numéro de catalogage de la pièce, ses dimensions, la matière, et parfois sa provenance ainsi qu'une brève description. 
Dans cette contribution, nous commencerons par retracer l'historique de la constitution des différentes collections archéologiques de la région de Vat Phu. Nous étudierons ensuite leurs spécificités en prenant pour exemple un certain nombre de pièces - classées par période et par type iconographique - que nous essaierons de replacer dans les contextes géographique et historique de leur création.

\section{Constitution des collections archéologiques de Vat Phu et premiers inventaires Les collections}

Les objets composant les « collections de Vat Phu »ont été rassemblés sous la supervision des autorités nationales lao à partir de la fin des années 1970 . Un peu plus tôt, le prince Boun Oum na Champassak (1912-1980), héritier de la maison princière du royaume de Champassak et grand amateur d'antiquités, s'était constitué une collection personnelle d'objets de diverses origines, dont les plus remarquables (aujourd'hui disparus) provenaient du complexe monumental de Vat Phu et de la ville ancienne. Après le départ du prince en 1975, ce fonds particulier semble avoir été laissé dans un premier temps à l'intérieur de sa demeure, à Champassak. Devenues par la suite « collection nationale ", les pièces qui le composaient furent presque toutes transportées dans des locaux administratifs où elles demeurèrent un bon nombre d'années. Seuls les vestiges archéologiques les plus encombrants (socles, pierres de seuil et grandes dalles préangkoriennes) restèrent dans la maison du prince : ils n'en bougèrent que récemment pour être apportés au musée de Vat Phu. Lors d'une mission d'expertise pour l'Unesco en 1986, Bruno Dagens signalait encore quatre dépôts pour les sculptures : deux dans la ville de Champassak - le bureau de la municipalité et un entrepôt - et deux à Paksé - le musée de la libération et le monastère de Vat Luang ${ }^{3}$. Les pièces conservées dans ce dernier ont été transférées il y a quelques années au musée de Paksé, rebaptisé depuis «musée du patrimoine historique de Champassak».

Avec le début des recherches archéologiques sur les sites de Vat Phu et de la ville ancienne, dans les années 1990 (PRAL ${ }^{+}$; Fondation Lerici ; etc.), les collections de Champassak se sont enrichies des nombreux éléments lapidaires mis au jour. En 1999, elles furent transportées dans une réserve plus vaste, qui existe encore aujourd'hui. Après le classement de Vat Phu sur la liste du Patrimoine mondial de l'Unesco en 2001, le site fut doté d'un organisme aux responsabilités élargies, le SAGV (service d'aménagement et de gestion du site de Vat Phu, devenu aujourd'hui le DVP), qui ne devint véritablement opérationnel qu'à partir de 2007. Si sa vocation initiale, similaire à celle d'APSARA ${ }^{5}$ à Angkor, était d'ordre patrimonial (restauration architecturale et recherches archéologiques), une certaine priorité fut toutefois attribuée à la mise en valeur touristique du site et au développement socio-économique qui devait en résulter. Des reliquats de la coopération japonaise avaient permis de construire en 2003 un bâtiment au pied du complexe monumental pour y loger les nouveaux services administratifs de la conservation. Rapidement,

3. Dagens 1986, p. 9.

4. Programme de recherches en archéologie lao. Ce projet de coopération franco-laotienne est dirigé par Marielle Santoni (CNRS, UMR 9993) et Viengkéo Souksavatdi (chef de la division des Antiquités, ministère lao de l'Information, de la Culture et du Tourisme).

5. APSARA : autorité pour la sauvegarde et l’aménagement de la région d’Angkor. 
une partie des collections de Champassak y fut apportée ${ }^{6}$, suite à l'aménagement d'une salle d'exposition et à la transformation d'une autre salle en réserve. L'espace de cette dernière fut cependant vite saturé, car la plupart des pièces furent posées dans un premier temps à même le sol, en l'absence d'équipements adéquats pour les accueillir. Les difficultés liées à l'exiguïté des locaux s'accrurent d'autant plus que, par une mesure de protection rendue nécessaire par la progression des vols, de nombreux vestiges laissés jusque-là sur leur site d'origine ou dans les monastères (conservatoires traditionnels, parfois eux-mêmes construits sur des sites khmers), tout comme les nouvelles pièces découvertes, vinrent progressivement s'ajouter aux collections du musée. Le problème a été momentanément résolu au cours de la mission que nous avons menée en 2010. Grâce à des dispositifs de rangement permettant d'optimiser l'utilisation de l'espace disponible, un réaménagement complet et fonctionnel de la réserve a été effectué.

\section{Les inventaires}

Au début du $x x^{\complement}$ siècle, les conservateurs d'Angkor effectuèrent quelques visites à Vat Phu, notamment Henri Parmentier en 1914 et Georges Trouvé en 1932 ${ }^{7}$. H. Parmentier dressa la liste des vestiges importants qu'il repéra sur le site ${ }^{8}$. À cette époque, les sculptures étaient rassemblées en majorité sur la terrasse supérieure, aux abords du sanctuaire principal (devant le petit édicule sud dit «bibliothèque ») ou à l'intérieur de celui-ci, près de l'autel aux Buddha modernes installé dans la salle hypostyle en grès et dans la cella en brique. Lors de son passage, G. Trouvé ne retrouva de la liste des objets établie par $\mathrm{H}$. Parmentier qu'une seule statue. Il s'agissait d'une divinité masculine debout à quatre bras, incomplète. Cette pièce, aujourd'hui disparue, semblait être un Viṣnu de l'époque du Bayon (fin $\mathrm{XII}^{\mathrm{e}}$-début $\mathrm{XIII} \mathrm{C}^{\mathrm{e}}$ siècle). Constatant les mauvaises conditions de préservation des stèles inscrites, le jeune conservateur en estampa plusieurs et conseilla au chef du village situé au pied du temple de protéger ces documents des intempéries. Deux parmi ceux-ci furent finalement transportés au musée de Phnom Penh : la très belle stèle dite « de Vat $\mathrm{Phu}$ » (K. 367), ornée en bordure supérieure du trident shivaïte, et une stèle digraphique $\mathrm{du} I \mathrm{X}^{\mathrm{C}}$ siècle (K. 362) relative au règlement des āśrama. Aujourd'hui entreposées à la conservation d'Angkor (CA 6835 et CA 6742), ces inscriptions, particulièrement belles, peuvent être admirées des visiteurs du musée de Vat Phu par le biais d'estampages qui ornent le mur d'entrée".

La plupart des pièces vues par H. Parmentier, si elles n'ont pas été repérées par G. Trouvé, ont en réalité subsisté et sont aujourd'hui conservées à Vat Phu. Certaines, cependant, restent bel et bien introuvables. Il en est ainsi d' " une curieuse pierre ornée sur chaque face de linga sous une arcature, trois sur chacun des grands côtés, un sur les deux petits ", avec une inscription qui courait à la base ${ }^{10}$. L'architecte rapprochait cette

6. Au cours du déménagement, certaines pièces qui appartenaient à des ensembles dans les locaux de Champassak furent dispersées, aussi les fragments de plusieurs sculptures se trouvent-ils aujourd'hui répartis dans les deux réserves.

7. Rapport pour la conservation d’Angkor (RCA), 1932. Document non publié.

8. Parmenticr 1914

9. Ces estampages ont été produits en 2010 par l'atelier de restauration du Musée national du Cambodge à Phnom Penh.

10. Parmentier 1914, p. 24, pl. XII, photo F, p. 56. 
pièce d'un piédestal allongé très étroit qui était posé à proximité "'. Comme il n'en avait pas pris les mesures, l'objet n'a pas pu être identifié.

En 1967, lors de son séjour au Laos pour une mission d'inventaire des collections royales du Vat Phra Keo à Vientiane, Madeleine Giteau fut invitée par le prince Boun Oum à expertiser ses collections de Champassak ${ }^{12}$. Seuls deux objets semblent avoir été photographiés par ses soins au cours de sa visite dans le sud : une tête de Viṣnu mitré préangkorienne en argent et un about décoratif angkorien en bronze, en forme de $n \overline{a g a}$ tricéphale aux capuchons dressés. Tous deux ont depuis disparu. Ni les dimensions exactes, ni leur origine précise (cf. infra) ne sont connues.

Par la suite, dans les années 1980 et 1990, d'autres spécialistes s'essayèrent à un inventaire descriptif des collections, mais aucun d'eux ne put prendre en compte l'ensemble des objets ${ }^{13}$. En 1993, dans le cadre des travaux du PRAL, nous avons procédé à un inventaire photographique complet, avec l'aide du photographe Christian Lemzaouda.

Le premier inventaire détaillé des sculptures remonte probablement à 1986, lorsqu'un conservateur, M. Bounlap Keokagna (secondé par M. Thongkoune Boriboune), fut envoyé à Champassak par le ministère laotien de l'Information et de la Culture. À cette date, seuls quelques objets collectés sur les principaux sites (Vat Phu, Nang Sida, Vat Luang $\mathrm{Kau}$ ) et les pièces de la collection du prince Boun Oum reçurent un numéro d'inventaire (un $K$ ou un $K h$ en alphabet lao, suivi d'un numćro en chiffre arabe). Un ensemble de 279 pièces fut ainsi inventorié. Les collections ayant été par la suite enrichies par l'entrée de nouveaux objets, l'inventaire donna lieu à des révisions. Un numéro supplémentaire fut ajouté à ceux qui existaient déjà et, pour les pièces provenant des fouilles, un code précisant le lieu de découverte fut indiqué. Pour des raisons de comptage peu claires, probablement dues aux déménagements successifs, d'autres numéros furent inscrits sur les pièces, parfois de façon disgracieuse et avec des peintures dommageables pour la pierre. Ce dernier système de référencement, toujours utilisé, présente les données dans l'ordre suivant: les initiales du site, suivies d'un chiffre romain indiquant la matière, puis le numéro de la pièce en chiffres arabes. La numérotation ayant été confiée à différentes personnes au cours de ces dernières années, de nombreuses erreurs et imprécisions en ont résulté. Par exemple, les sites de provenance ne sont pas toujours indiqués par les mêmes initiales (au site de Vat Luang Kau sont ainsi attachées les initiales BMK, BWLK ou VLK - ces dernières étant également celles utilisées pour le Vat Lakhon). Les objets de même matière n'apparaissent pas non plus systématiquement sous le même chiffre romain. Aux statuettes en résine végétale (keson dok mai) recouvertes d'or ou d'argent ont ainsi été associés les chiffres II (métal), III (métal précieux), V (bois) ou X (résine végétale). Certains objets sont également entrés au dépôt sans être tout de suite notés et leur lieu de provenance est maintenant oublié. Lorsque le numéro de pièces nouvellement marquées n'a pas été reporté immédiatement dans le cahier d'inventaire, des doublons dans la numérotation ont pu par ailleurs se produire. On constate encore le cas de pièces qui n'ont pas reçu le même numéro d'inventaire dans le cahier et sur l'objet. De nombreuses confusions ont aussi résulté du fait que des vestiges - dont l'origine était en fait inconnue - ont été marqués sous les initiales du temple de Vat Phu (VP), considérant que celles-ci incluaient un espace large. Sur les 167 pièces marquées VP, dont 87 sont en pierre, on peut ainsi considérer qu'une cinquantaine seulement proviennent réellement du

11. Ibid, p. 23.

12. Giteau 1969, p. 64. Cf. également son Art et archéologie du Laos (Giteau 2001).

13. Dagens 1986 ; Michel Jacq-Hergoualc`h et John Guy, communications personnelles. 
complexe monumental. Le problème se pose pour les objets de l'ancienne « collection Boun Oum » qui héritèrent tous des initiales VP, sauf les quelques grosses pièces préangkoriennes (socles, marches, dalles) et les bai-sema modernes transfërés récemment, qui sont catalogués sous les initiales HBO et HBH (Heuan Boun Oum/Houm). Enfin, des erreurs se sont produites lorsque des numéros partiellement ou entièrement effacés ont été réinscrits ; il est arrivé que les nouveaux numéros ne correspondent plus à rien ou alors à d'autres objets.

En 2004, à l'occasion de l'installation des sculptures dans le tout nouveau musée de Vat Phu, Patrizia Zolese ${ }^{14}$ et son équipe constituèrent le premier inventaire sous forme de base de données. Celui-ci répertoriait 400 objets ${ }^{15}$. Valérie Zaleski (musée Guimet) créa en 2008 une nouvelle base au format Works pour les pièces exposées. Ce travail fut repris et complété par nous à partir de 2009 - tout en donnant lieu à un changement de support, puisque la base de données fut transférée sous format Access par David Bazin, informaticien. Notre projet visant à l'exhaustivité - il s'agit désormais de couvrir l'ensemble des collections archéologiques de la province de Champassak - les incohérences des inventaires manuels mentionnées précédemment ont durement affecté notre tâche. Au terme des quatre mois de la première mission (2009), la quasi-totalité des pièces ont toutefois pu être retrouvées, ainsi que leur numéro ${ }^{16}$. Sur près de 1500 pièces inventoriées, les collections comptent plus de 950 vestiges en pierre, 309 objets en métal ou comportant du métal, 74 pièces en bois ou en résine végétale et 160 en terre cuite ${ }^{17}$.

La base de données, qui sera à terme accessible au public via Internet, est encore en cours de constitution. La phase de l'intégration des collections les plus anciennes ayant été achevée, il s'agit maintenant de l'augmenter par les inventaires d'objets découverts au cours des campagnes du PRAL (1991-1999), ce qui devrait permettre d'atteindre les 2000 entrées. Seuls les objets issus des fouilles et prospections menées par les missions archéologiques récentes autres que celles du PRAL ont pour le moment été laissés de côté, en l'absence de documents relatifs au contexte de leur découverte.

\section{Le musée de Vat Phu}

L'unique salle d'exposition (fig. 2) du musée de Vat Phu accueille des pièces de toutes les périodes, depuis la préhistoire tardive jusqu'au $x x^{6}$ siècle. La plus grande partie de l'espace est toutefois réservée aux collections khmères. Ces pièces relèvent des époques préangkorienne et angkorienne. Leur présentation est thématique, l'espace imparti ne permettant pas une présentation chronologique des objets. Ce choix date de la première installation des pièces en 2004 et a été respecté lors du réaménagement des collections en août 2010. Les thèmes abordés sont les suivants : épigraphie, shivaïsme, vishnouisme,

14. Directrice de l'archéologie pour la fondation Lerici, institut polytechnique de Milan.

15. Le fichier, trop ancien, n'a pu être récupéré, le parc informatique du DPV ayant depuis été renouvelé.

16. Pour pallier certains problèmes de numérotation évoqués plus haut, nous avons par exemple différencié les doublons par l'ajout d'un indice. De nombreux fragments dispersés ont par ailleurs été rassemblés.

17. Les collections khmères sont constituées de 734 pièces en pierre et de 43 pièces de métal. Près d'une dizaine de céramiques de grande taille et en bon état, datant de l'époque angkorienne, sont issues de la collection Boun Oum. Les autres céramiques entrées à l’inventaire (une centaine de fragments) proviennent des fouilles ou des prospections menées par les diverses missions archéologiques. Les milliers de tessons collectés au cours de ces campagnes constitueront à terme un tessonnier de référence pour la région. 
bouddhisme ancien, architecture (frontons, linteaux, colonnettes, antéfixes, éléments de toiture, etc.), divinités et animaux gardiens, vie quotidienne (mobilier domestique en pierre et en céramique), bouddhisme laotien. Une vitrine sécurisée permet d'exposer une petite partie du fonds des objets et statuettes en matériaux précieux (bronze, or et argent), qui provient en grande partie des fouilles effectuées par le PRAL entre 1991 et 1999. Certaines pièces lapidaires importantes ne sont pas encore exposées, car elles nécessitent au préalable une restauration. Celles qui sont présentées au public donnent cependant un bon aperçu de leur diversité et de leurs spécificités stylistiques. Elles sont également les indices de l'importance du potentiel archéologique que recèlent encore les sites de la région (peu de fouilles ont été effectuées) et permettent d'appréhender une partie de son histoire. Les pièces préangkoriennes sont nombreuses, notamment pour la statuaire. Plusieurs d'entre elles appartiennent à la période la plus ancienne et témoignent de styles originaux, inconnus ailleurs dans le monde khmer. Quant aux éléments d'architecture exposés, ils relèvent essentiellement de l'époque angkorienne et proviennent en majorité du temple de Vat Phu.

Dans cette contribution, nous présenterons les collections en les classant par ordre chronologique. L'étude ne pouvant être exhaustive, nous porterons notre attention sur plusieurs pièces exposées, mais également sur des objets conservés dans les réserves qui présentent un intérêt scientifique particulier. Seront abordées successivement la période préhistorique, les périodes préangkorienne et angkorienne, puis les collections d'art bouddhique lao. Le fonds Boun Oum se caractérise par un certain nombre de sculptures appartenant à un art local tardif, dont aucun exemple n'est exposé. Elles seront toutefois également traitées, en raison de leur originalité et des questions qu'elles soulèvent.

Pour les collections relevant du monde khmer, nous avons tenu compte dans cette présentation de quelques pièces qui ont disparu, mais qui restent connues par des photographies ou par des descriptions. Nous ferons également référence à des objets, peu nombreux, qui sont exposés à Paksé ou dans des musées plus lointains (Vientiane, Hanoi, Paris).

\section{La période préhistorique}

Parmi les quelques objets pouvant être datés de la période préhistorique, seules deux haches polies (BWLK I 671 ; PP I 672) et un grattoir (VP I 514) sont exposés au musée de Vat Phu. Tous ont été trouvés en surface lors de prospections pédestres. Aucun site préhistorique préservé n'est connu dans la région à ce jour. Le grattoir provient du temple de Vat Phu, mais les fouilles du PRAL effectuées sur la terrasse supérieure, dans la zone de la source (1991-1993), ont montré que l'abri sous roche où sourdent les eaux sacrées a été entièrement nettoyé à l'époque khmère et que ces travaux ont détruit toute trace d'une éventuelle occupation antérieure. La hache provenant de Vat Luang Kau (BWLK I 671) est incomplète, l'extrémité du tranchant étant brisée. De dimension importante $(27,2 \mathrm{~cm}$ de long) et de très belle facture, elle a été taillée dans un grès dense parfaitement lissé. L'objet est très sonore et pourrait être aussi identifié comme un élément de lithophone. Quelques autres haches polies et grattoirs provenant de la ville ancienne, du temple de Vat Phu et de Houay Tomo sont exposés au musée de Paksé.

Une dizaine de vases, pots et coupes sur pied, à pâte beige et ornés de motifs peints en rouge typiques du style de Ban Chiang, sont conservés dans la réserve de Vat Phu (VP VI 9, 28, 31, 33 à 36, 41). Ces objets, tous complets et en excellent état, faisaient partie de la collection du prince Boun Oum. Leur authenticité nous paraît sujette à caution. 


\section{La période préangkorienne}

Les premières formes plastiques et monumentales qui se sont développées dans la région de Vat Phu remontent au début de la période préangkorienne et constituent donc des témoignages archéologiques rares. Nous leur accorderons une attention toute particulière, car elles relèvent d'un art encore en cours de maturation. Les pièces préangkoriennes les plus nombreuses proviennent de la ville ancienne et de sa proche région. Un certain nombre de vestiges ont été également retrouvés dans le complexe monumental de Vat Phu, bien que celui-ci ait étė daté jusqu'à présent de la seule période angkorienne. Ces découvertes confortent l'hypothèse d'une installation cultuelle khmère très longue.

\section{Les pièces préangkoriennes provenant de la ville ancienne et de la périphérie de Vat Phu}

\section{Les inscriptions}

Plusieurs inscriptions retrouvées dans la ville ancienne et dans la périphérie de Vat Phu sont conservées au musée du site. La stèle dite « de Vat Luang Kau » (VLK I 736, $\mathrm{n}^{\circ}$ d'inscription K. 365) en est le fleuron : elle fait partie des plus anciens témoignages en langue sanskrite connus à ce jour dans la péninsule Indochinoise. Retrouvée au début $\mathrm{du} \mathrm{Xx}^{\mathrm{e}}$ siècle au cour même de la ville ancienne - à l'embouchure du Houay Sa Houa ou peut-être un peu plus au sud, sur les terres dépendant de la mission catholique - elle se présente sous la forme d'une borne quadrangulaire de 1,80 $\mathrm{m}$ de hauteur, gravée de seize lignes sur chaque face, et prolongée par un long et large tenon carré aux angles coupés, ayant fonction de pilier. Datée paléographiquement de la deuxième moitié du ve siècle, l'inscription commémore vraisemblablement la « fondation » de la ville ancienne située en bordure du Mékong. Le Mahārājādhirāja (grand roi des rois) Devānīka, " venu de loin », aurait créé là un mahātīrtha nommé Kurukśetra qu'on associe aujourd'hui à cet espace de $4 \mathrm{~km}^{2}$, délimité par des doubles remparts de terre. À l'intérieur de l'enceinte, les vestiges de plus d'une trentaine de monuments ont été repérés, fréquemment associés à des bassins ${ }^{18}$.

Deux autres inscriptions sanskrites (K. 1173 et K. 1174), conservées aujourd'hui dans la réserve de Champassak, présentent un intérêt majeur pour l'histoire de la région. Composées de quelques lignes, elles sont gravées sur deux piédestaux cubiques retrouvés sur le site de Houay Sa Houa 2 (HSH2), à Ban Vat Luang Kau, à la limite amont de la ville ancienne. Il s'agit de dédicaces, datées par Claude Jacques de 590. Chacune mentionne l'érection d'une image du Taureau (dit Nandin) par le prince Citrasena (le futur roi Mahendravarman), pour le bénéfice de son père Viravarman et de son oncle Krtantapasa. Ces inscriptions tendent à confirmer que la région de Vat Phu est bien le berceau d'une dynastie qui contribuera à fonder l'empire khmer et à laquelle les rois angkoriens chercheront par la suite à se rattacher. Il est à noter que les dimensions du socle du Taureau préangkorien exposé au musée de Vat Phu (VP I 369, cf. infra), qui provient du même village, ne correspondent à aucun des deux piédestaux.

Un peu moins ancienne, une stèle incomplète (PSE I 543, non exposée) retrouvée sur le site de Phon Sao-é, hors de l'enceinte de la ville du côté ouest, a livré une inscription difficilement déchiffrable, mais où C. Jacques a pu tout de même lire le nom de Jayavarman I.

18. Sur les travaux réalisés dans la ville ancienne par le PRAL entre 1993 et 1998, cf. Santoni 2008. 
Une inscription trouvée à une cinquantaine de kilomètres plus au sud, sur deux piédroits de porte du sanctuaire de Houay Kadienne (district de Mounlapamok), mentionne également ce souverain. Le territoire de Vat Phu était donc encore sous l'influence de la même dynastie khmère à la fin du $\mathrm{VII}^{\mathrm{E}}$ siècle. D'autres fragments d'inscriptions de petite taille, conservés dans la réserve de Vat Phu, comportent quelques caractères anciens ou des lignes tronquées qui sont difficilement exploitables.

\section{Les éléments architecturaux}

Deux linteaux préangkoriens ont été trouvés à Ban Vat Luang Kau, au cœur de la ville ancienne. Celui qui est exposé au musée de Champassak (VP I 419) a été découvert dans une rizière près du site de HSH2 et appartient au style de Sambor Prei Kuk (fig. 3). Les deux makara, chevauchés par des joueurs de tambour, crachent - en même temps que l'arc à double courbure - un cheval qui apparaît à mi-corps. Au point d'inflexion central de l'arc, un garuda mi-anthropomorphe, figuré dans un médaillon ovale, tient dans chaque main un nāga. L'autre linteau, qui a été photographié en 1970 par Jean Filliozat sur les terres de la mission catholique, est aujourd'hui exposé au musée de Paksé. Son ornementation est proche de celle de la pièce précédente, mais la queue des makara-qui forme plusieurs rangées de feuilles (ou de plumes) - est particulièrement développée. Le style des figures de ces deux linteaux, particulier à la région, apparaît très archaïque ${ }^{19}$.

Un fragment de linteau sculpté de guirlandes florales pendant sous un arc courbe que décoraient des losanges curvilignes avait été vu sous une maison du village de Nong Vienne et photographié par le PRAL en 1991, lors de prospections dans la ville ancienne. Il semble aujourd'hui disparu. Ses caractéristiques iconographiques permettaient également de le rattacher à la série des linteaux appartenant à la période de Sambor Prei Kuk.

D'autres parties de linteaux appartenant à la même période sont présentés au musée de Paksé, l'un d'eux est probablement plus tardif dans la mesure où le makara est stylisé.

Un linteau présentant des caractéristiques stylistiques l'apparentant au style de Prei Khmeng vient d'être trouvé en surface sur le tertre de Nong Moung (ville ancienne), fouillé en 2011 par le PRAL. Brisé, seuls deux fragments ont été retrouvés (un troisième fragment, au moins, est manquant). Le décor des médaillons en fleurons est entièrement végétal; l'arc à double courbe est ourlé de guirlandes.

Un autre linteau du même type (style de Prei Khmeng avec réminiscences du style de Sambor Prei Kuk) a été récemment découvert dans les ruines du sanctuaire de Phu Malong, situé à mi-chemin entre Champassak et Paksé.

Sept somasūtra préangkoriens terminés par une tête de makara ont été retrouvés à Vat Phu ou dans sa proche région. L'un d'eux (HSH I 551, 1-2), placé dans la réserve, provient des fouilles du site de HSH2. Parmi les trois pièces qui sont exposées au musée, une est originaire du site de Houay Tomo, sur la rive gauche du Mékong ${ }^{20}$. Seul le somasütra de Khoh Khong (VP I 465), ramené en 1986, est dans son état complet.

Un conduit de somasūtra coudé en angle droit a par ailleurs été trouvé en surface sur le site de Nong Moung, probablement rejeté là par les pilleurs du temple. Bien que très

19. Benisti 1974, p. 154-155 et fig. 27 ; Le Bonheur 1988, p. 73-74 et fig. 20.

20. Parmentier 1927, t. 1. p. 14 et fig. 1. 
érodé et incomplet, il ne semble pas s'être terminé par une tête de monstre. Il s'agit du seul conduit d'évacuation des eaux de ce type connu à ce jour ${ }^{21}$.

Quelques colonnettes circulaires incomplètes se rattachant apparemment aux styles de Sambor Prei Kuk et de Prei Khmeng, d'une parfaite exécution, sont présentées au musée. Certaines sont soulignées par de riches guirlandes à brins multiples qui s'entrecroisent. Les fûts nus sont ornés de bagues à fleurons. Sur les quelques extrémités de fûts conservés, le bulbe est assez développé. Un fragment de section circulaire, au fût lisse cerclé d'une bague lisse doublée d'un filet en relief, a été retrouvé dans le périmètre sud-est de la ville ancienne. Une autre colonnette - engagée - de forme octogonale et probablement un peu plus tardive, provient de Phou Lek (VP I 458).

Une pièce d'accent en forme de corne (HSH I 607) mise au jour à HSH2, témoigne d'une forme originale jamais rencontrée précédemment dans l'art khmer (non exposée) ${ }^{22}$. Enfin, parmi les autres éléments architecturaux conservés à Vat Phu, on peut rappeler sept pièces qui faisaient partie de la collection Boun Oum : trois pierres de seuil dont une en demi-lune (HBO I 735) et deux en accolade (HBO I 811,812); trois grandes dalles plates (HBO I 730, 731, 733), dont une percée de deux trous (crapaudines ?) ; et un socle en grès cubique à percement central carré ( $\mathrm{n}^{\circ} \mathrm{d}$ 'inv. perdu). Elles datent du début de la période préangkorienne et ont probablement été découvertes dans la ville ancienne.

\section{La statuaire shivaïte}

Hors du complexe monumental de Vat Phu, peu d'éléments préangkoriens pouvant être rattachés à Śiva ont été retrouvés dans la région, bien que des piédestaux prévus pour des linga (à ouverture centrale circulaire) aient été repérés dans la ville ancienne. Aucune statue du dieu n'a été identifiée parmi les quelques corps à deux bras conservés dans les réserves. Il semble figuré uniquement sous la forme du linga. Deux de ces images sont exposées : l'une provenant du sommet du Lingaparvata, la montagne sacrée (PK I 487); l'autre, de grande taille, découverte dans le village de Ban Muang Kang, en bordure du Mékong (BMK I 737). Les deux linga ont été sculptés dans un bloc monolithe faisant corps avec la snānadroṇī. Dans les deux cas, le gland et le filet sont indiqués en relief.

Nous avons signalé plus haut le Taureau couché provenant probablement du village de Vat Luang Kau (VP I 369), qui est exposé au musée. Cette pièce, de grande taille $(\mathrm{H}: 51 \mathrm{~cm}, \mathrm{~L}: 108 \mathrm{~cm})$, est d'une parfaite exécution et en très bon état de conservation (fig. 4). Les formes sont pleines; les bijoux en sont absents.

Un très beau Ganeśa debout préangkorien originaire de la région de Vat Phu est présenté au musée de Vientiane.

21. Un autre somasītra, celui-ci doublement coudé en angle droit, a cependant été retrouvé au Prasat Boran IK 321 près de That Badom dans la région de Stung Treng (Cambodge). Cf. Parmentier 1927, p. 226-230. Vat Phu est distant de quelque $150 \mathrm{~km}$ du confluent de la Sékong où de nombreux vestiges de monuments anciens ont été retrouvés. Les deux régions semblent avoir entretenu des contacts, comme l'indiquent plusieurs éléments lapidaires d'un style comparable. Sur l'importance de la Sékong, cf. la communication prononcée à Berlin lors de la $13^{\text {e }}$ conférence de l'EurASEAA ( 27 septembre- $1^{\text {cr }}$ octobre 2010), par Phon Kaseka, Tran Ky Phuong et Thonglith Luangkhot («An archeological survey along the Sekong riverbanks in Southern Lao ").

22. Santoni 1998, fig. 14, p. 18. 


\section{La statuaire vishnouite}

Six statues préangkoriennes liées à l'iconographie vishnouite sont exposées au musée de Vat Phu : trois Viṣṇu, une Devī et deux Viṣnu montés sur Garuḍa ${ }^{23}$. Les trois dernières ont été retrouvées sur le site du complexe monumental et seront présentées plus bas. Les trois Viṣnu sont parcellaires et en mauvais état de conservation. Ils sont cependant reconnaissables soit à la mitre, soit à la massue, soit au vêtement. En tout, plus d'une quinzaine d'images vishnouites préangkoriennes (comprenant deux images de Devī) ont été retrouvées dans la région. Il s'agit en majorité de rondes-bosses de grande taille. L'un des corps présentés (VTH I 526), conservé auparavant au Vat Thong (fig. 5), mesure $138 \mathrm{~cm}$, du bord inférieur de la jupe à la naissance du cou; une tête (VP I 210, origine inconnue), mesure $42 \mathrm{~cm}$ de hauteur. Cette dernière a perdu la presque totalité des détails du visage suite à la desquamation du grès. Le dieu est toujours figuré debout, pourvu de quatre bras. Le vêtement permet de déterminer deux groupes de représentations : celles vêtues du long dhoṭi indien à pan médian, et celles portant un pagne court maintenu par un nœud central, qui retombe en un pan médian plissé repassant à l'arrière entre les jambes. Ici, l'ajustement n'est pas un critère de datation, puisque les deux traditions semblent avoir coexisté ${ }^{24}$. Quelques pièces sont inachevées, mais on distingue sur deux d'entre elles (VP I 37 ; VP I 78) la mitre ainsi que la massue et les arcs de soutien qui permettent de les rattacher à la même période. Sous une maison proche du site de Nong Vienne avaient été vus, avec le fragment de linteau que nous avons mentionné plus haut, les pieds sur base à tenon d'une statue brisée aux chevilles (pièce non retrouvée). Les traces d'arrachement d'un instrument circulaire sur le côté gauche du socle, probablement une massue, permettaient de restituer là encore une image de Vișnu. Un fragment aujourd'hui disparu de Viṣnu à jupe (partie inférieure du corps, de la taille aux genoux) gisait en surface sur le site de Nong Deunh. Un autre a été trouvé à proximité de Paksé, à une quarantaine de kilomètres au nord de Vat Phu; il est conservé dans la réserve du musée de la ville. Une ébauche de Vișṇu mitré tenant la massue, avec arcs de soutien, provenant de la région de Champassak, est présentée au musée de Vientiane.

La magnifique tête de Vișṇu en argent aux lèvres rehaussées d'or photographiée par M. Giteau dans la maison du prince Boun Oum en 1967 - elle est aujourd'hui disparue vient compléter cette série. Nous ne connaissons pas ses dimensions exactes, mais elle est décrite par le prince Doan Na Champassak comme étant « grandeur nature » ${ }^{25}$. M. Giteau la date du début du vIII ${ }^{\circledR}$ siècle. La présence de courtes boucles de cheveux calamistrées dépassant de la mitre sur les tempes, qu'on retrouve sur les Viṣnu plus anciens, permet de la rattacher plutôt à la première moitié du VII siècle. Si elle peut être considérée comme un témoignage de la richesse de la région à la période préangkorienne, son origine exacte n'est pourtant pas connue. Le prince Doan Na Champassak indique qu'elle aurait été trouvée dans une mare de Champassak vers 1962. D'après les récits des villageois, elle pourrait provenir du site de HSH2 et avoir été exhumée lors du creusement d'un bassin pour le camp militaire installé à côté du Vat Luang Kau dans les années 1970. Ce bassin a largement entamé l'édifice central d'où proviennent les deux socles de statues du Taureau

23. Des notices sur le corps du Vișnu VTH I 526, la tête VP I 210 et la Devī VP I 485 sont publićes dans le catalogue du musée de Vat Phu (Hawixbrock et al. 2012).

24. Voir les Viṣnu préangkoriens exposés au musée de Phnom Penh (Jessup \& Zćphir 1997 et Dalsheimer $2001)$.

25. Na Champassak 1972. 
portant une dédicace de Citrasena. Le monument semble composé de trois monticules qui pourraient correspondre à trois bâtiments. Il est possible que l'un des deux autres sanctuaires ait été dédié au dieu Vișṇu, ce qui n'est pas incompatible avec un contexte shivaïte, chacun des temples ayant pu abriter l'un des dieux de la Trimürti. Cette tête en argent est le seul fragment de statue en métal précieux connue à ce jour dans la rćgion de Vat Phu. Un socle (PNT I 756 1,2,3) conservé dans les réserves du musée pourrait toutefois être le second témoin de l'existence de statues en métal ${ }^{26}$.

Les statues vishnouites de la région de Vat Phu témoignent d'une grande qualité plastique. Elles montrent une musculature puissante et parfois un léger embonpoint, comme les corps VTH I 526 et VP I 407 (fig. 5, 6). Elles témoignent également du culte important qui était rendu à Viṣnu de la fin du vic jusqu'au début du VIII siècle, dans un territoire que le shivaïsme marquait pourtant profondément (rôle du Lingaparvata). Deux inscriptions préangkoriennes rendent hommage au dieu : d'une part, la stèle de Vat Luang Kau (K. 365), qui mentionne l'érection d'une image de Viṣnu ; d'autre part, une stèle provenant des éboulis au nord du temple de Vat Phu, datée du règne de Jayavarman I, qui relate l'érection par un svāmin d'un autel à Viṣnu Nārāyaṇa (K. 1059) ${ }^{27}$.

Il semble qu'à la fin du $\mathrm{vl}^{\mathrm{e}}$ siècle, Vișnu - divinité royale par excellence (il porte la coiffe du cakravartin) - ait été particulièrement vénéré par les rois khmers. Son image, grâce au commerce maritime, a largement été diffusée dans les états côtiers de la péninsule Malaise ${ }^{28}$. On peut alors se demander si les statues trouvées dans la région de Vat $\mathrm{Phu}$, bien que certaines soient plus tardives, ne participent pas de la même propagation du culte de ce dieu dans tout l'espace indianisé ${ }^{29}$. Il faudra attendre ensuite le XII' siècle, autre époque où Viṣnu est particulièrement honoré dans le monde khmer ancien (il sera la divinité d'élection de Sūryavarman II), pour retrouver à Vat Phu la mention de l'érection d'images qui le représentent (cf. infra) ${ }^{30}$.

M. Giteau mentionne une autre pièce préangkorienne sans provenance précise de l'ancienne collection Boun Oum, elle aussi disparue ${ }^{31}$. Il s'agit d'une statue masculine debout à deux bras, d'une excellente exécution, mais non identifiable en l'absence d'attributs ${ }^{32}$. Le visage, aux yeux simplement gravés, est souriant. La chevelure est

26. Il provient du village de Phanon Tai, situé aux abords de la ville ancienne, côté sud, en bordure du Mékong. Lisse et de forme presque cubiquc, il cst taillé dans un grès gris très friable (brisé en trois fragments). Il porte sur la face supérieure les empreintes de pieds sculptées en léger creux. Une cavité circulaire en forme de cône inversé est percée au centre de chacun des talons. Très profondes, ces cavités sont tellement étroites qu'il est impossible d'y ficher des tenons en pierre. Il faut plutôt restituer là l'espace nécessaire à deux tenons de métal, les empreintes devant permettre de caler les pieds d'une image en matériau précieux, soutenue également par un tenon postérieur ainsi que l'indique une mortaise rectangulaire située en retrait, à l'arrière, entre les empreintes. Leurs dimensions ( $23 \mathrm{~cm}$ de longueur) permettent de restituer une statue d'un mètre de haut environ. Le monastère du village. Vat Phanon Tai, conserve dans un des bâtiments une ébauche de Viṣnu mitré debout à quatre bras. Ce temple est installé sur un site préangkorien important au vu des vestiges visibles en surface sous les installations modernes.

27. Lintingre 1974, p. 516-517.

28. Manguin \& Dalsheimer 1998.

29. Cf. également les nombreux Viṣnu appartenant à l'art de Dvāravatī, retrouvés notamment sur le site de Dong Si Mahapot en Thaïlande, site dont provient également le cakra vishnouite de grande taille que nous mentionnons plus bas (Brown 1996).

30. Cl. l'inscription K. 366 (XII' siècle) qui mentionne l'installation de plusieurs images de Vișnu et de Srī ainsi qu un Harihara (Cœdès 1953, p. 288-295).

31. Giteau 2001, p. 63, fig. 15.

32. Pour l'identification de cette image, cf. Lintingre 1972, p. 216. 
formée de multiples rangs de boucles calamistrées qui retombent sur les épaules. Les lobes des oreilles sont étirés et percés, mais ne portent pas de boucles. La musculature du buste nu est indiquée avec soin ; un pagne court et lisse vient couvrir les cuisses en biais, depuis la taille. Un long pan médian, lisse et plat, tombe entre les jambes à l'avant. Selon M. Giteau, cette statue date du vIII" siècle et relève de la fin du style du Phnom Da. Mais ses caractéristiques iconographiques, très proches de celles du Paraśurāma nº 1641 du Phnom Da conservé au Musée national de Phnom Penh ${ }^{33}$, permettent de la rattacher aux sculptures datées aujourd'hui de la fin du VIe-début VII siècle.

\section{Les pièces bouddhiques}

Plusieurs Buddha préangkoriens ont été retrouvés dans la région qui entoure Vat Phu. Six d'entre eux, fragmentaires, proviennent du Vat Lakhon, un monastère lao de la ville de Champassak. Trois têtes, dont une de taille monumentale (VLK I 530, hauteur : $84 \mathrm{~cm}$ ), sont exposées au musée de Vat Phu; une quatrième est présentée au musée de Paksé. Deux Buddha assis en méditation (VLK I 531 ; VNK I 782 ${ }^{34}$ ) sont également répartis dans ces deux musées. Les pièces du musée de Vat Phu, étudiées par Valérie Zaleski, présentent des influences stylistiques en relation avec l'art de Dvāravatī et peuvent être datées de la fin du vII" ou du début vIII" siècle. Deux Buddha similaires à la plastique assez plate sont conservés dans les réserves (VP I 99, VP I 402). Aucune fouille n'avait jusqu'ici été entreprise au Vat Lakhon, bien que les traces d'une structure en brique soient visibles à l'arrière de son domaine, sur la piste en terre qui dessert la ville du côté de l'intérieur des terres. L'élargissement de la route en 2010 a en partie arasé ces vestiges. Nous avons pu repérer au moment des travaux plusieurs lits de briques d'un gros module préservés sur les bas-côtés de la route. Par la suite, un sondage archéologique a été effectué par M. Bounlap Keokagna. Il laisse supposer l'existence d'au moins un monument de grande taille, non daté pour le moment (les Buddha proviennent d'un autre tertre situé plus à l'ouest sur les terres appartenant au monastère). La taille des briques et des éléments d'architecture en grès situés à proximité font pencher pour une datation préangkorienne du monument.

Une datation semblable à celle donnée pour les pièces du Vat Lakhon peut être proposée pour le corps brisé à la taille d'un Buddha en costume monastique - assis à l'européenne (VP I 74) - dont l'origine exacte est inconnue (fig. 7) ${ }^{35}$. Ses pieds reposent sur une base ovoïde. On peut remarquer l'absence du trône, qui laisse supposer que cette statue devait prendre place dans une niche pourvue d'une banquette. Les mains sont perdues et ne reposaient pas dans le giron, puisqu'aucune trace d'arrachement n'est visible. Le corps très érodé d'un Buddha debout en costume monastique (VP I 414), dont les avant-bras perdus étaient à l'horizontale, date sensiblement de la même période (VIII" siècle ?). Conservé dans le dépôt de Vat Phu, il provient de la province de Champassak, mais son origine précise est inconnue. Une tête de provenance elle aussi incertaine (VP I 329), en mauvais état et de petite taille (soclée sur bois), est exposée au musée. Elle présente une coiffure en grosses boucles et pouvait donc appartenir à un Buddha préangkorien.

33. Dalsheimer 2001, p. 74-76. Le style des boucles de la coiffure des deux statues est tout à fait comparable.

34. VNK et VLK font référence au même monastère, dont le nom peut s'écrire indifféremment Vat Nakhon ou Vat Lakhon.

35. Cf. la notice de Valérie Zaleski dans le catalogue du musée de Vat Phu (Hawixbrock et al. 2012). 
Bien qu'aucune pièce d'obédience bouddhique n'ait été retrouvée dans la ville ancienne de façon certaine, les fouilles du site de Nong Vienne ont révélé l'existence de deux structures circulaires accolées, qui sont peut-être des stüpa ${ }^{36}$. Cet ensemble complexe pourrait dater de la fin du $\mathrm{VI}^{\mathrm{C}}$ siècle ou de la première moitié du $\mathrm{VII}^{\circledR}$ siècle. Seuls les soubassements des deux structures circulaires en brique sont en partie conservés. Leurs rétrécissements successifs en paliers sont ornés de motifs répétitifs en redents plats, qui ne sont pas sans rappeler l'ornementation architecturale des stüpa appartenant à la culture de Dvāravatî. L'accès à la plateforme supérieure se faisait par des escaliers axiaux. Les échiffres étaient décorés de plaques en grès figurant des édifices en réduction d'une taille supérieure à ceux connus ailleurs dans le monde khmer. Trois de ces bas-reliefs ont été retrouvés en place lors des fouilles (NV I 536-538), et deux d'entre eux sont exposés au musée de Vat Phu. Ils avoisinent un mètre de haut et représentent un monument vu de face, pourvu d'un avant-corps placé sur un haut soubassement mouluré. Un escalier axial conduit à une porte fermée au battant médian décoré de dés carrés. La couverture n'est pas différenciée de l'arc en fer à cheval des frontons. Celui de l'avant-corps, seul visible, est orné d'une demi-fleur épanouie en éventail aux pétales pointus, dont la longueur $s$ 'adapte à la forme en arc de cintre. La base et l'arrière des plaques sont pourvues d'un tenon de fixation. Le style de ces plaques d'échiffres, tout comme celui d'un motif en grès visible en surface sur le site de Vat Sang'O (ville ancienne), est proche de celui des édifices en miniature qui scandent le soubassement de certaines cellules de méditation du site de Han Chei, au Cambodge. On peut également les comparer à certains bas-reliefs sculptés sur les façades des sanctuaires en brique de Sambor Prei Kuk et à ceux de la corniche du sanctuaire de Kuk Prah That (province de Kompong Cham, VII'-VIII siècle). Le soubassement du grand chedi de Si Thep, récemment dégagé, est également scandé de niches surmontées d'arcs en plein cintre - destinées peut-être à abriter une image de Buddha - qui ne sont pas sans rappeler la forme générale des plaques d'échiffre de Nong Vienne. Au Champa, des architectures fictives ornent également les soubassements de temples et de piédestaux ${ }^{37}$.

\section{Les objets en relation avec la vie quotidienne}

Un grand nombre d'objets en relation avec la vie quotidienne - mortiers et pilons, égrugeoirs et rouleaux, râpes à santal - ont été retrouvés dans la ville ancienne et les autres sites de la région. Ils ne diffèrent pas de ceux trouvés ailleurs dans le monde khmer. On peut voir au musée une sélection de ces objets avec leurs variantes. Le plus rare est probablement une peșani en forme de rhinocéros provenant du village de Ban Kateuap (BKT I 467). C'est à notre connaissance le seul égrugeoir zoomorphe connu à ce jour. Le dos du rhinocéros forme la table dormante. Le rendu de l'animal est réaliste et bien observé, témoignant de la maîtrise technique du sculpteur. Il en existait un second, que nous avons photographié en 1991 dans le périmètre sud-est de la ville ancienne (il avait été ramassé par des villageois lors du creusement d'une rizière), mais il a disparu depuis plusieurs années.

Nous laisserons de côté dans cette présentation la céramique préangkorienne. Représentée par des milliers de tessons issus des fouilles et des prospections, leur étude débute à peine.

36. Santoni 1998.

37. Baptiste 2005, p. 110-111. 


\section{Les pièces préangkoriennes provenant du temple de Vat Phu}

La stèle de Vat Luang Kau, gravée au cours de la seconde moitié du v siècle, indique que le Lingaparvata était « connu depuis l'antiquité ». L'existence ancienne d'un sanctuaire sur la montagne est par ailleurs mentionnée dans les annales chinoises (Histoire des Sui). Bien qu'aucune trace d'un sanctuaire primitif ne soit visible sur la terrasse supérieure, des vestiges de cellules monolithes en grès, probablement préangkoriennes, sont présentes dans sa partie nord. Un sondage effectué dans cette zone en 1991 n'a pas apporté d'informations probantes. La totalité de la terrasse supérieure est loin d'avoir été fouillée, mais les recherches menées autour de la source ont montré qu'il était vain d'espérer y trouver des structures anciennes, puisque la roche a été entièrement nettoyée lors de l'édification au $\mathrm{XI}^{\mathfrak{E}}$ siècle des aménagements architecturaux (templion, allée couverte, etc.) et du dispositif de captation des eaux sacrées. H. Parmentier voyait dans la cella en brique du sanctuaire principal une reprise postérieure, et non une construction d'époque préangkorienne ${ }^{38}$. Les dégagements du PRAL sur le côté nord du bâtiment (1995) ont confirmé que les briques de la cella couvraient largement le raccord à la salle hypostyle en grès. Il est possible que le sanctuaire actuel remplace un sanctuaire plus ancien installé sur le même emplacement. Des fouilles à l'intérieur de la cella pourraient confirmer cette hypothèse. Les vestiges préangkoriens retrouvés épars sur le site sont en tout cas suffisamment nombreux pour qu'on puisse déjà admettre l'existence de structures architecturales antérieures aux bâtiments visibles aujourd'hui ${ }^{39}$.

\section{Les inscriptions}

Seules deux inscriptions préangkoriennes ont été découvertes sur le site même de Vat Phu : la belle stèle ornée du trident shivaïte qui mentionne des dons à un sanctuaire situé sur le Lingaparvata sous le règne de Jayavarman I (K. 367, ramenée à la conservation d'Angkor), et un fragment trouvé en surface dans l'avant-corps hypostyle du sanctuaire (K. 876, entré au musée de Hanoii) ${ }^{40}$. Les autres sont des inscriptions rupestres, dans les éboulis de rochers au nord du temple (K. 1059) et dans la grotte de Tham Lekh (K. 723724) située dans la montagne au-dessus du complexe monumental.

\section{Les éléments architecturaux et le mobilier cultuel}

Les vestiges préangkoriens retrouvés à Vat Phu sont pour la plupart des éléments architecturaux et du mobilier cultuel. Ceux qui ont été mis au jour au cours des fouilles du PRAL (1991-1995) étaient systématiquement placés dans un contexte de réemploi ou de rejet. Une partie des pièces découvertes a été ré-enfouie sur place à des fins conservatoires - dont un élément d'encadrement de porte à bossettes ${ }^{41}$. Des colonnettes (VP I $457,461,463$ ) et un socle (musée de Vientiane) ont été retrouvés brisés du côté nord du sanctuaire, lors des fouilles en 1995 (fig. 8).

Deux séries d'éléments décoratifs particulièrement intéressants ont été découverts, soit en surface, soit dans un contexte de réemploi (fouilles PRAL 1991-1992). Il s'agit

38. Parmentier 1927, vol. 1. p. 231.

39. PRAL, campagnes de fouilles 1991 à 1995. Cf. Santoni et al. 1991.1997 el 1998.

40. Cf. la chronique du $B E F E O 37$, p. 604.

41. Santoni et al. 1998, fig. 12, p. 17. Une pièce similaire, elle aussi ré-enterréc sur place, a été retrouvée sur le site de HSH2. 
de plaques entièrement décorées de motifs végétaux, ou ornées de visages en bas-relief placés sous des arcatures végétales (candraśálā ou kự̂u). Un exemplaire de chaque type a été retrouvé dans la cella en brique, sans qu'on sache s'il s'agit véritablement de leur emplacement d'origine.

Les cinq plaques à décor végétal conservées au musée proviennent exclusivement de Vat Phu (VP I 106, 559 à 561, 581). L'une d'entre elles (VP I 559) avait déjà été vue et photographiée par $\mathrm{H}$. Parmentier, qui l'identifiait à une antéfixe ${ }^{42}$. Elle est aujourd'hui en très mauvais état. Les formes de ces pièces sont diverses : trois ont l'aspect d'un fleuron en losange (VP I 559 à 561 ), deux sont carrées (VP I 106, 581). Leurs dimensions varient entre 30 et $70 \mathrm{~cm}$ de hauteur. Toutes présentent la particularité d'être percées près de leur centre. Le décor est formé par des rinceaux en crosses végétales qui se déploient depuis l'orifice central sans réelle symétrie.

Le second groupe de plaques décoratives est constitué de huit candraśālā aux provenances diverses. Cinq sont originaires de Vat Phu, deux ont été retrouvées en surface sur le site du temple de Houay Tomo (dont TM I 464) et une (VP I 728) est dite venir de la région, sans autre précision. Quatre de ces pièces sont exposées au musée de Vat Phu et deux autres au musée de Paksé. L'une d'elles (VP I 583) fut retrouvée comme élément de pavage d'un dallage tardif devant l'abri sous roche d'où sourd la source. Érodés et incomplets, les visages en bas-relief sont inscrits dans des lucarnes dont l'arc semble être toujours en plein cintre et ourlé de rinceaux. Les coiffes sont de deux types : certains portent une sorte de bonnet conique lisse arrondi au sommet (VP I 583 ; fig. 9), les autres un diadème à trois ou cinq pointes (VP I 197 ; fig. 10). Le seul point commun de ces visages, aux traits par ailleurs diversifiés, est leur parure : de grosses boucles d'oreille circulaires, parfois ornées d'une fleur épanouie. La majorité de ces pièces sont également percées d'un trou de fixation ; l'une d'elles est munie d'un tenon inférieur.

Ces vestiges d'époque préangkorienne sont difficiles à dater avec précision. Il n'existe pas d'équivalent, ailleurs dans le monde khmer, de plaques de grès percées ayant pu constituer des éléments de plaquage. Les visages sous arcature ne sont cependant pas sans rappeler l'ornementation des temples chams ; on les retrouve également dans l'art de Dvāravatī, ainsi que dans l'art de Java Central. À Sambor Prei Kuk, de semblables motifs sont figurés sur les palais volants des bas-reliefs de brique des sanctuaires. Sur le même site, des personnages sculptés en bas-relief arborent des coiffes et des boucles d'oreille d'un type similaire, tels des bonnets à pointe recourbée très proches de ceux de la tradition indienne. Les motifs des plaques décoratives à rinceaux ne sont pas sans rappeler, eux aussi, ceux qu'on rencontre à la fois dans l'art cham et dans celui de Dvāravatī. Dans ces deux séries de pièces, aucune sculpture n'est identique à une autre, leur aspect général et leur taille étant toujours sensiblement différents. Elles étaient probablement destinées à orner les façades de monuments de brique, sans pour autant présenter un motif répétitif. Si elles ne rythmaient pas les corniches et les faux étages des tours, comme le suppose H. Parmentier, elles étaient alors peut-être encastrées sur les parois extérieures des sanctuaires, en position centrale, comme pour les palais volants en bas-relief des monuments de Sambor Prei Kuk.

Deux grandes et minces dalles rectangulaires à la fonction indéterminée (VP I 547 et 548), ornées en leur centre d'un lotus épanoui, participent de la même mouvance stylistique, ainsi qu'un élément de corniche au bandeau vertical sculpté d'une frise de gaṇa atlantes de type cham (VP I 415). 
Deux somasütra incomplets ont été retrouvés à Vat Phu. L'un d'entre eux (tête et départ du canal) provient du sanctuaire central. Il est exposé au musée de Vientiane. Le second (VP I 93) est présenté au musée de Vat Phu (seule la tête est conservée).

Aucun piédestal préangkorien complet n'a été retrouvé à Vat Phu, hormis celui qui est exposé au musée de Vientiane. Seule une pierre à dépôt de piédestal (VP I 601), presque cubique et de petite taille $(14 \times 16 \times 16 \mathrm{~cm})$, a été mise au jour dans la zone de la source (PRAL 1993). Le plat supérieur de la pièce est orné d'une fleur de lotus épanouie à double rang de pétales. Le cœur de la fleur forme la cavité circulaire centrale, ornée sur son pourtour d'étamines incisées verticalement. Huit cavités carrées sont inscrites dans les pétales du lotus.

Un lion d'échiffre préangkorien (VP I 84), debout sur ses quatre pattes (brisées), était placé sur la terrasse supérieure du temple. La gueule est largement ouverte, la crinière en fort relief forme quatre rangs de touffes de poils pointues qui passent sous les oreilles et couvrent largement la nuque. La queue recourbée est plaquée contre l'échine. Ces caractéristiques stylistiques, notamment le traitement de la crinière, permettent de le rattacher à la fin de la période préangkorienne.

La représentation d'un joueur de harpe barbu sur un fragment de fronton (?) posé jusqu'à récemment près du sanctuaire central de Vat Phu a été rapprochée par M. Giteau de celle de l'un des musiciens du linteau de Sambor Prci Kuk figurant la danse de Śiva $\left(\mathrm{MNC}, \mathrm{n}^{\circ} 1748\right)^{43}$. S'il s'agit bien de la pièce présentée aujourd'hui au musée de Paksé (fig. 11), le style du personnage est sensiblement différent de celui des figures du linteau de Sambor Prei Kuk et évoque l'art cham. Ce bas-relief n'est pas sans rappeler, par son exécution maladroite, le groupe de pièces «d'art local tardif» de la collection Boun Oum (cf. infra). On peut douter d'ailleurs que ce soit un élément de fronton. Si on considère la forme et la faible épaisseur du bloc ( $15 \mathrm{~cm}$ environ), il s'agit plus probablement d'une plaque décorative.

\section{La statuaire shivaïte}

Quelques linga, difficiles à dater avec précision, pourraient appartenir à la période préangkorienne. Ceux qui sont exposés au musée de Vat Phu ont été mis au jour autour du templion et sous l'abri sous roche lors des fouilles de 1991 à 1993. Il s'agit de deux linga bi-partites et de deux pancalinga. Les deux premiers possèdent respectivement une base cubique (VP I 566) et une base octogonale (VP I 567). Le rudrabhāga est bombé et le gland est indiqué en relief. L'un des deux pancalinga fait corps avec le piédestal complet. Le dé, lisse, présente la particularité d'avoir des parois incurvées, comme le piédestal exposé à Vientiane. Cinq petits linga sont sculptés en quinconce à l'intérieur de la snānadroṇi, un dans chaque angle, le cinquième (de taille supérieure) au centre. L'autre pièce (VP I 597), haute de $16 \mathrm{~cm}$, présente une forme générale plus ramassée, presque cubique (fig. 12). Le piédestal, qu'on devine à ses angles moulurés, sert de chevet aux quatre linga périphériques sculptés presque en haut-relief au centre de chacune des faces verticales. Le linga sommital, aplati, est en ronde-bosse. La snänadron̄i n'est pas indiquée. Un linga préangkorien, de forme bombée avec gland en relief (base brisée), est par ailleurs exposé à Paksé.

Cinq Taureaux couchés, en ronde-bosse, ont été retrouvés sur le site (VP I 86, 173, $278,369,563$ ), en dehors de leur contexte d'origine. De petite taille (une quarantaine de

43. Boisselier 1955, pl. 16; Dalsheimer 2001, p. 184. 
centimètres en moyenne, en hauteur comme en longueur), ils sont tous incomplets et ont perdu leur tête. Ils sont difficiles à dater et ne sont pas présentés au public.

Deux Gaṇeśa provenant de Vat Phu ont également été identifiés (VP I 79, 757), dont un de taille monumentale. Ce dernier gisait en surface, renversé et brisé en plusieurs fragments sur la pente sud, au niveau de la terrasse qui forme le premier palier de la montée vers le sanctuaire. Bien que très incomplet (la face, les bras, la partie supérieure du buste et la totalité de l'abdomen sont manquants), il est possible de le restaurer. Aucune parure n'est visible. De ce fait, il est également difficile à dater.

\section{La statuaire vishnouite}

Un corps de Vișnu préangkorien de petite taille $(65 \mathrm{~cm}$ de hauteur, pieds brisés), vêtu du dhoțin, est exposé au musée de Vat Phu (VP I 40). La tête et les quatre bras sont manquants. Il présente les mêmes caractéristiques anatomiques (formes assez pleines et léger embonpoint) que la grande statue VTH I 526.

Deux Garuḍa préangkoriens sont également exposés au musée. Le premier (VP I 80), ailes déployées et corps dans une attitude d'envol - était installé dans l'abri sous roche près de la source, sans qu'on sache s'il s'agissait là de son emplacement d'origine. Le second (VP I 167/214) accueillait Viṣnu assis à califourchon sur ses épaules (seules les jambes du dieu subsistent). En très mauvais état, brisé à la taille, il peut être daté de la

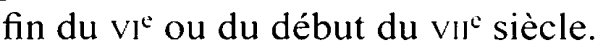

Une statue préangkorienne de Devī (VP I 485) a été dégagée récemment dans la digue ouest du baray nord de Vat Phu (fig. 13) ${ }^{44}$. Cette très belle pièce de petite taille $(58 \mathrm{~cm}$ de haut), incomplète (mains inférieures et pieds manquants) et brisée en sept fragments, est taillée dans un grès gris au grain très fin. Le visage arbore une expression sévère. Les yeux, petits et indiqués uniquement par incision, sont enfoncés dans les orbites. Les lèvres particulièrement charnues n'esquissent aucun sourire. La mâchoire est large et carrée. Coiffée de la mitre qui couvre totalement la chevelure, la divinité est vêtue d'un sarong qui remonte haut sur la taille, qu'elle a particulièrement fine. Le vêtement lisse à long pan médian est orné d'un drapé en poche latéral à triple pli. Une ceinture lisse, portée en léger biais, donne un semblant de déhanchement à cette statue pourtant frontale. L'arc de soutien prend appui sur la mitre à l'arrière. Les deux mains supérieures, seules conservées, tiennent le cakra à droite et la conque à gauche. Les particularités de cette image permettent de la rapprocher du style de Prei Khmeng.

Une tête de divinité préangkorienne maintenant exposée au musée (VP I 815) a été trouvée en 2010 par l'équipe de l'Archeological Survey of India (ASI) dans le quadrangle nord, lors du dégagement d'un tas de déblais situé devant l'angle sud-ouest (fig. 14). Sculptée dans un grès doré sableux, elle est malheureusement assez érodée. La chevelure, indiquée sur le crâne par des stries verticales, est ramenée au sommet de la tête en un court chignon conique au sommet aplati. Un unique rang de mèches en anses retombe sur son pourtour. Les mèches temporales sont verticales. Le visage à la mâchoire carrée nous paraît plus masculin que féminin. Il pourrait s'agir d'une tête de Śiva, mais aucun signe visible (troisième œil ou croissant) ne permet de l'identifier avec certitude. Bien qu'aucune statue de Śiva de cette période ne nous soit parvenue, on sait par les rares 
exemples de Harihara conservés qu'il était bien coiffé d'un jațāmukuṭa de forme tout à fait comparable à celui des déesses ${ }^{45}$.

Une tête féminine du même type a été trouvée sur le site de Ban Nong Sa (BNS I 714). Très abîmée, seuls la partie postérieure de la tête et le sommet du crâne sont conservés, le visage ayant été intentionnellement scié (fig. 15). La coiffure est tout à fait comparable à celle de la tête précédente. La chevelure est ramenée en bandeaux lisses verticaux sur le crâne, mais le haut chignon étroit est ici formé de deux étages de mèches en ancre sur la partie antérieure visible. La large mèche postérieure couvre largement le crâne au-dessus de la nuque. Sur celle-ci, les mèches latérales en ancre ne sont pas recouvertes par la mèche postérieure, et les mèches temporales sont verticales. Une autre tête féminine présentant des caractéristiques semblables a été photographiée par M. Giteau près du sanctuaire principal en 1964 (fig. 16) ${ }^{46}$. Cette pièce, à cause de sa coiffure simplifiée, lui paraissait un peu plus tardive (VIII siècle) que la Devī de Koh Krieng (Sambor du Mékong) conservée au Musée national du Cambodge. M. Giteau datait cette dernière de la fin du VII ${ }^{\mathrm{e}}$-début du $\mathrm{VIII}^{\mathrm{e}}$ siècle, mais elle est rattachée aujourd'hui à la première moitié du VII siècle ${ }^{47}$. Elle arbore un large et haut chignon maintenu par un double lien à la base et à mi-hauteur, retenant un double rang de mèches en anses devant, et un quadruple rang à l'arrière du crâne. La coiffure de la tète de Vat Phu disparue est beaucoup plus simple. Le chignon, plus petit, est de forme plutôt conique et aucun lien visible ne maintient l'unique rang de mèches en anse, plus longues à l'arrière que devant. Les anses latérales, dissymétriques, s'incurvent vers l'arrière et passent sous la mèche postérieure. Autre différence, les rangs de mèches parallèles - verticales sur les côtés de la tête pour la pièce de Koh Krieng sont obliques et infléchies en courbe ascendante vers l'arrière du crâne sur la tête de Vat Phu. Les trois pièces retrouvées sur le site du complexe monumental et à Ban Nong Sa appartiennent en tout cas bien à la même famille. Elles sont suffisamment proches pour qu'on puisse leur attribuer une origine locale commune.

Un fragment de roue en grès rouge (VP I 785), de quelque $50 \mathrm{~cm}$ de diamètre, a été retrouvé en 2008 sur la terrasse supérieure de Vat Phu, peut-être près de la sala moderne située au nord du sanctuaire (fig. 17). Identifié jusqu'à présent à une roue de la Loi (dharmacakra), ce vestige est exposé dans l'espace réservé au bouddhisme du musée de Vat Phu. Cependant, les caractéristiques de ce cakra sont assez différentes de celles connues dans l'art de Dvāravatī. Il possède un moyeu de grande taille, bombé et en fort relief, limité par deux moulures en décrochement. Il était peut-être orné à l'origine, au moins sur une face, d'un motif disparu sous l'usure. De ce moyeu partaient des rayons très courts, dont cinq seulement sont conservés. La tranche de la roue est surmontée par une mince arête en relief ornée de dents triangulaires, les pointes tournées vers l'extérieur. Les mêmes motifs sont sculptés dans l'espace intermédiaire entre les rayons, en deux séries opposées se faisant face. On trouve bien sur quelques dharmacakra ces mêmes motifs triangulaires sur le pourtour et dans l'espace intermédiaire entre les rayons, mais la ressemblance s'arrête là - puisque pour ces cas particuliers la forme du moyeu reste conforme à celle des autres roues de la Loi ${ }^{+8}$. Sur la pièce de Vat Phu, le moyeu montre

45. Boisselier 1955, p. 99.

46. Giteau 2001, p. 64, fig. 16. Cette pièce avait disparu lorque M. Giteau repassa à Vat Phu en 1969

47. Dalsheimer 2001, p. 89 : Jessup \& Zéphir 1997, p. 170.

48. Brown 1996, fig. 42. Un fragment en terre cuite trouvé dans la province de Nakhon Si Thammarat montre, sur le pourtour de la roue, une série de motifs triangulaires pointus. L'auteur 
en effet un traitement très différent, sans indication de percement fictif ou d'axe en relief pour l'essieu ${ }^{49}$. En fait, l'aspect général de cette roue est beaucoup plus proche de celui des cakra tenus par des Viṣnu préangkoriens ${ }^{50}$. Un cakra d'assez grande taille $(17 \mathrm{~cm}$ de diamètre) retrouvé seul à Dong Si Mahapot (province de Prachin Buri, Thaïlande) est similaire ${ }^{51}$. Le disque de Viṣnu possède, au moins aux époques les plus anciennes, un moyeu bombé qui occupe la majorité de l'espace central. Les rayons du cakra sont courts et son pourtour extérieur se termine en règle générale par une arête vive. Cependant, la taille du vestige de Vat Phu, assez petite pour une roue de la Loi, est un peu trop grande pour un cakra vishnouite tenu par une divinité en ronde-bosse dans l'une de ses mains supérieures. On peut supposer l'existence d'une statue de Vișnu de taille monumentale, mais aucune image de ce type n'a été retrouvée à Vat Phu, pas même à l'état de fragments. Il est vrai que rien ne certifie que le site soit bien le lieu d'origine de cette roue ; elle a pu être amenée là à une date indéterminée ${ }^{52}$. Peut-être faut-il alors conclure à une représentation indépendante du symbole ? Il existe au moins deux stèles figurant des Trimürti abstraites. L'une est conservée au musée Guimet ${ }^{53}$, la seconde a été retrouvée dans une région proche de Vat Phu, à proximité de la rivière Sekhaman (province de Sékong, Laos $)^{54}$. Toutes deux figurent Śiva au centre sous la forme du trident, Brahmā à droite sous la forme du vase et du rosaire, et Vișnu à gauche sous la forme de la roue, surélevée au sommet d'un pilier. Si on ne connaît pas de figuration abstraite de grande taille de la Trimürti, en revanche, des piliers sommés d'une image du Taureau en rondebosse existent dans le monde préangkorien ${ }^{55}$. Il se pourrait que cette roue vishnouite ait été placée de même au sommet d'un pilier.

Toutes les pièces préangkoriennes retrouvées à Vat Phu nous semblent confirmer l'implantation d'un sanctuaire très ancien sur la terrasse supérieure, en rapport avec la source sacrée. Au sommet du Lingaparvata même, aucune structure monumentale n'a été repérée jusqu'à présent. Seules deux pièces préangkoriennes (exposées au musée) ont été trouvées à la base de l'éminence rocheuse, en 1994 : le linga sur cuve à ablutions monolithe (PK I 487) et une petite base aux angles redentés (PK I 488). La découverte par le DPV de briques et de blocs de grès taillés au sommet de cette éminence, en janvier

reproduit également un bas-relief provenant du Gandhara qui illustre le Premier Sermon, conservé au musée de Calcutta (fig. 88). Les quatre roues qui y sont figurées possèdent entre les rayons, partant de la roue, le même type de motifs.

49. Les trois types de moyeu connus sont reproduits dans le catalogue de l'exposition Dvāravatī, 2009, in Rungot Thamrungrueang 2009, fig. 3, p. 85.

50. Voir le Harihara (MG 14910) de l'Asram Maha Rosei (province de Ta Kéo) appartenant au style du Phnom Da et daté de la fin du vic-début du vil siècle in Baptiste \& Zéphir 2008, p. 53 ; ainsi que le cakra d'un Viṣnu (MG 18860) provenant de Prasat Rup Arak sur le Phnom Kulen, appartenant au style du Kulen, daté de la deuxième moitié du Ix ${ }^{\mathfrak{C}}$ siècle, op. cit., p. 91-92.

51. Brown 1996, fig. 93.

52. C'est le cas des linga détachés du rocher de Khan Mak Houk qui ont été apportés près du sanctuaire principal de Vat Phu (cf. infra).

53. MG 24618, datée de la seconde moitié du vil siècle, provenant de Tuol Komnap, province de Kratié (Baptiste \& Zéphyr 2008, p. 48-49).

54. Cf. la communication inédite de Phon Kaseka et al. (citée en note 21 ); cf. également la contribution de M. Lorrillard dans ce volume.

55. Ainsi le Taureau sur pilier d'Angkor Borei qui était, semble-t-il, placé à l'entrée de la ville. Aujourd'hui conservé au musée Guimet (MG 14930), il est daté des vil"-vill" siècles (Baptiste \& Zéphir 2008, p. 50-51). 
2011, semble toutefois prouver l'existence d'un aménagement ancien. De gros module, les briques pourraient en effet appartenir à la période préangkorienne.

\section{La période angkorienne : le complexe monumental de Vat Phu}

La ville ancienne et ses abords immédiats n'ont livré que des éléments en pierre datant de l'époque préangkorienne, même si des fragments de céramique montrent une occupation probablement plus tardive. Les constructions de l'époque angkorienne semblent s'être limitées aux bâtiments qui forment le complexe monumental proprement dit de Vat Phu, à flanc de montagne, et à ceux qui sont placés un peu plus au sud, dans la plaine, comme les temples de Nang Sida (XII ${ }^{e}$ siècle) et de Thao Tao (chapelle d'hôpital du règne de Jayavarman VII, fin XII'-début XIII ${ }^{\mathrm{e}}$ siècle).

Si les temples qui forment cet ensemble sont peu nombreux, ils sont toutefois un peu mieux documentés que les sites préangkoriens. L'origine des pièces angkoriennes est en règle générale connue, même si elle manque parfois de précision. Rappelons qu'une ville était probablement associée à ces monuments (des levées de terre et des canaux sont visibles sur les photographies aériennes).

\section{Les inscriptions}

Quelques stèles inscrites de l'époque angkorienne ont été trouvées à Vat Phu. Certaines doivent être restaurées avant d'être exposées. Les fragments de l'une d'elles (K. 1005, VP I 149 et 452) ont pu être rassemblés grâce aux observations de D. Soutif et de J. Estève ${ }^{56}$. Une pièce difficile à déchiffrer a été retrouvée à Vat Phu sous plus de deux mètres de terre en 1901 (VP I 150, K. 477) ${ }^{57}$. Haute de plus de trois mètres, elle se présente comme un long bloc quadrangulaire au sommet arrondi, pourvu d'un tenon de fixation. Les quatre faces sont inscrites, les lignes couvrant la quasi-totalité de la surface. Le texte est en grande partie effacé, car la pierre a servi d'aiguisoir à couteaux en plusieurs endroits.

\section{Les éléments d'architecture}

Les éléments architecturaux sont pour la plupart typiques des styles du Baphuon et d'Angkor Vat ( $\mathrm{XI}^{\mathrm{C}}$-XII' siècle). L'inventaire actuel compte 47 pièces en grès provenant de Vat Phu, ainsi que quelques pièces originaires de Houay Tomo et de Nang Sida. Aucun vestige de la chapelle d'hôpital de Thao Tao n'a encore été catalogué. Il est probable qu'un bon nettoyage des pentes de la montagne autour du temple de Vat Phu permettrait de dégager de nombreux autres éléments lapidaires.

Des éléments architecturaux qui avaient été longtemps laissés in situ sont maintenant exposés au musée du site. Une partie de fronton (VP I 128) provient du quadrangle sud (fig. 18), tout comme un linteau (VP I 24) issu de son porche nord. Ils sont sculptés de rinceaux, au centre desquels figure une divinité masculine accroupie tenant la massue (Vișnu, Kubera ?). La seconde pièce pourra être remise en place si les conditions architectoniques le permettent (chantier de restauration DPV/FSP). Seule une base de pilastre, sculptée de deux rşī sur le dé (VP I 113), n’a pas d'origine connue.

56. Cf. leur contribution dans ce volume.

57. Voir la chronique du $B E F E O$ 1, p. 162. 
Des linteaux et des parties de rampants appartenant aux frontons triangulaires des quadrangles et du sanctuaire principal (stylistiquement semblables à ceux de Prah Vihear) sont conservés dans les réserves. Au musée, sont exposées d'autres pièces provenant de Vat Phu : un élément de chapiteau (VP I 20), des pilastres d'angle octogonaux (VP I 162,120 et 279), un motif de couronnement en forme de lotus (VP I 136) et un dé de porte orné d'un lotus épanoui à double rangs de pétales, trouvé en surface en 1995 près du sanctuaire principal (VP I 615).

Presque tous les éléments en grès qui permettaient l'ondoiement permanent du linga du sanctuaire principal à partir des eaux de la source ont été ré-enfouis après leur découverte, lors des campagnes du PRAL. Ce système d'adduction constitue l'une des installations les plus originales du sanctuaire de Vat Phu. Les eaux sacrées étaient menées par des sections de canalisations à couvercles montées sur des colonnettes jusqu'au linga principal. L'eau pénétrait dans la cella par une ouverture percée dans la paroi ouest. Seuls deux couvercles de canalisation appartenant à cette structure sont conservés au musée du site (VP I 442 et 613$)^{58}$, mais ils ne sont pas présentés au public. Pourvus d'une arête sommitale, ils sont ornés d'une rangée de pétales de lotus sur les faces verticales. On peut se demander si l'ensemble n'évoque pas le corps d'un näga.

Des trente et une antéfixes retrouvées à Vat Phu, trois sont exposées au musée (VP I 55,56 et 405 ) et une au musée de Vientiane. Si la majorité de ces pièces figure un ascète debout tenant à deux mains le long manche d'un trident, plusieurs illustrent toutefois des divinités masculines non identifiables. Beaucoup sont en mauvais état. Celles qui sont exposées au musée du site montrent un ascète armé du trident (VP I 405), une représentation d'Indra monté sur Airāvata monocéphale (VP I 55) et une divinité masculine assise à califourchon sur les épaules d'un autre personnage masculin (V'P I 56) : Viṣnu sur Garuḍa à forme humaine ou Nirrti chevauchant le vaksa. Un Yama monté sur le buffle (VP I 9) est conservé dans la réserve de Champassak. Ces antéfixes devaient être placées sur les tours en fonction de leur orientation cardinale. Quant aux acrotères, ils figurent tous des nāga polycéphales et proviennent des quadrangles nord et sud. Certains pourraient être remis en place.

Deux fragments de dalles à dépôt de fondation supérieures en grès rouge (VP I 534 et VP I 519) proviennent de Vat Phu. Ces vestiges sont comparables à ceux trouvés ailleurs dans le monde khmer. La dalle mince, carrée, devait être partagée en quatre quartiers, chacun creusé de cavités d'aspects variés (circulaires, en fer de lance, carrées, etc.), dont une en forme d'arc. Un fragment de pierre à dépôt de fondation circulaire ayant conservé deux cavités carrées (VP I 570), trouvé en 1992 dans la zone de la source, pourrait avoir été placé sous le motif de couronnement d'une tour.

\section{Le mobilier cultuel}

Quelques piédestaux de type angkorien, à ouverture circulaire ou carrée, sont conservés dans les réserves. Aucun n'est complet, puisque les cuves à ablutions retrouvées (dont certaines sont de grande taille) ne s'adaptent pas aux différents socles.

De nombreuses pierres à dépôt de fondation de piédestaux angkoriens cubiques, de tailles diverses et à multiples cavités carrées, ont été retrouvées. Six pièces en bon état sont exposées au musée. 
Cinq exemplaires de pierres à offrande (balipittha) ont été retrouvés en dehors de leur contexte d'origine. L'une provient de Nang Sida, les quatre autres de Vat Phu. Deux d'entre elles sont exposées (VP I 111 et VP I 130). De hauteurs variables, toutes sont ornées d'une fleur de lotus épanouie à double rang de pétales, sculptée en bas-relief sur le plat supérieur de la pierre.

Parmi les autres éléments qu'on peut qualifier de mobilier cultuel, il faut mentionner deux cuves en grès. L'une, exposée au musée, vient de Nang Sida (HNS I 492); l'autre, repérée en 2010, est encore in situ à Vat Phu. Elle gisait en surface sur la pente de la

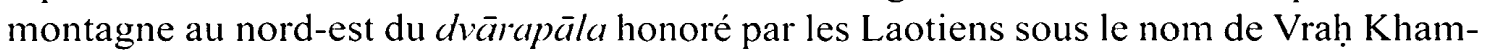
mathan (roi mythique constructeur du temple). Dans les deux cas, seule la partie basse est conservée. Sur la cuve de Nang Sida, le trou médian inférieur percé sur l'une des faces longues est placé à l'intérieur de la gueule ouverte d'un masque de lion (fig. 19). Sur celle de Vat Phu, il semble que ce soit un Rāhu ou un kīrtimukha à bras qui entourait le trou d'écoulement, puisque le seul motif préservé est un bras plié à angle droit, orné d'un brassard.

\section{La céramique architecturale}

De très nombreux tessons de tuiles ont été mis au jour autour des quadrangles nord et sud et dans la zone de la source, de part et d'autre de l'allée couverte en charpente qui reliait l'abri sous roche au mur d'enceinte ouest du temple. Une restitution partielle de toiture angkorienne réalisée par Pierre Pichard (EFEO) et Laurent Delfour (assistant technique du DPV) est présentée au musée du site. Elle montre comment les tuiles canal et les tuiles couvre-joints étaient disposées ; sont également présentés des épis de faîtage en terre cuite, de formes et de pâtes de couleurs diverses, ainsi que des tuiles d'about. La majorité de ces dernières figure un pétale de lotus ; quelques-unes sont ornées de cinq hampes végétales sinueuses. Une tuile originale (VP VI 200) montre la représentation de deux chevaux de profil, s'affrontant de part et d'autre d'un axe central vertical. Une autre tuile, ornée d'un visage stylisé aux larges yeux en amande, est exposée au musée de Paksé. Il semble - si le cartel est exact - qu'elle ait été trouvée sur le site préangkorien de Nong Saphang Yai, situé dans l'angle nord-ouest de la ville ancienne. On peut rapprocher cette tuile à visage d'un bloc de grès à fausses tuiles d'about (VP I 555) trouvé en 1995 au nord du sanctuaire principal (PRAL) et présenté pour le moment avec les candraśălā au musée de Vat Phu (fig. 20). Unique en son genre, ce dernier est sculpté de trois bustes de personnages masculins sous des arcatures végétales en arc brisé. Seule la représentation centrale est complète, les deux autres étant coupées par les limites du bloc. Le personnage de gauche, d'une taille supérieure aux deux autres, indique qu'un jeu de motifs venait peut-être interrompre la monotonie des bordures des toitures. Les têtes portent un diadème feuillu et sont ornées de grosses boucles d'oreille circulaires et d'un collier de perles ; les visages sont moustachus. Le style est très proche de celui d'une tuile d'about en céramique que nous avions trouvée lors des fouilles du temple de Phanom Van ( $\mathrm{x}^{\mathrm{C}}$ siècle, nord-est de la Thaïlande) en $1993^{59}$. Ceci indique que le même modèle a pu être décliné indifféremment en pierre et en terre cuite. Les autres blocs en grès à fausses tuiles d'about conservés dans les réserves proviennent des deux quadrangles et sont décorés de pétales de lotus. Ils possèdent une banquette de pose postérieure, alors 
que le bloc cité précédemment est pourvu de tenons inférieurs. Probablement intégré à une maçonnerie, celui-ci pouvait orner la corniche d'un bâtiment en brique.

Le musée du site expose également un clou de charpente en fer (VP IV 4), ainsi qu'une ancre en fer en double T (VP IV 3), trouvée dans la zone de la source lors des fouilles, qui a conscrvé sa gangue de plomb. Les ancres avaient pour fonction de maintenir solidaires deux blocs de grès dans le chaînage des assises horizontales.

\section{Les divinités gardiennes des bâtiments}

De nombreuses images de divinités peuvent probablement être reconnues comme des dikpāla, les "gardiens de l'espace ». Assises à la javanaise et adossées à des chevets, elles ont été, dans leur grande majorité, rapportées dans les réserves. Huit des mieux conservées sont toutefois présentées au public. L'une d'elles (VP I 43), sans collier mais portant diadème, triple chignon, boucles d'oreille et bracelet au poignet droit, tient un objet allongé dans sa paume gauche, peut-être un livre. Le vêtement dégage l'épaule droite, mais couvre entièrement le bras gauche. Une écharpe est pliée par-dessus le vêtement sur l'épaule gauche. Il pourrait s'agir d'une retaille postérieure destinée à transformer cette divinité gardienne en une divinité bouddhique : elle fut en effet longtemps conservée sur l'autel bouddhique du sanctuaire de Vat Phu, bien postérieur au bâtiment qui l'abrite, puisque d'époque lao. Sur une autre pièce (VP I 42), le bec déverseur de la cuve à ablution est indiqué. C'est donc un piédestal complet qui a été sculpté, au lieu du socle mouluré sur lequel les divinités gardiennes sont habituellement assises. Celles qui ont conservé leur tête arborent une coiffure à trois pointes et un diadème. La plupart portent de nombreuses parures : boucles d'oreille et gorgerin, collier de poitrine, bracelets et brassards. Les chevets sont en règle générale décorés en bordure des deux faces et dans la partie médiane de la face postérieure de perlages et de motifs végétaux. Aucune de ces divinités n'est identifiable, la plupart ayant perdu mains et attributs.

Un corps de divinité assise en aisance royale (VP I 73), d'une belle exécution, est à distinguer des probables dikpāla. Contrairement à ces derniers, toujours adossés à un chevet, il est sculpté en ronde-bosse. Le buste est nu et le seul vêtement porté est un sampot court et lisse. La main droite est posée sur le genou relevé, la main gauche repose à plat sur la base à l'arrière de la cuisse en un mouvement bien observé. L'identification est impossible en l'absence d'attributs. On peut se demander si cette pièce, qui pourrait appartenir au style du Bayon, ne serait pas la figuration d'un personnage humain plutôt que celle d'une divinité.

Les autres figures gardiennes sont animales. Les pièces présentées au public sont un éléphant (dinnāga ?) en ronde-bosse, au cou orné d'un riche collier à rangs multiples et à grelots (VP I 81), et quatre grands lions d'échiffres, deux ouvrant la visite des collections dans la salle d'exposition (VP I 388 et 389), deux autres étant disposés à l'entrée de la sala située en face du musée (VP I 13 et 14).

Quelques extrémités de balustrades à tête de năga polycéphale sont conservées. Une seule, à cinq têtes, est exposée au musée (VP I 64). Une autre pièce a été dégagée en 2010 par les spécialistes indiens du même tas de déblais que la tête préangkorienne citée plus haut. De taille plus imposante, elle est constituée de sept têtes. Restaurée et placée devant le quadrangle nord, elle est devenue immédiatement un objet de culte pour les Laotiens. Il est possible qu'elle ait été placée à l'origine en bordure de l'allée qui permet d'accéder aux deux quadrangles. 


\section{La statuaire shivaïte}

Aucune image de Śiva sous sa forme humaine n'avait jusqu'ici été identifiée à Vat Phu, en dehors de la figure centrale de la Trimïrti qui a été sculptée en bas-relief sur un rocher au nord-ouest de la cella du sanctuaire principal ( $\mathrm{x} \|^{\mathrm{e}}$ siècle). Une ronde-bosse de taille moyenne $(50 \mathrm{~cm}$ de longueur), illustrant Śiva et Uma montés sur le Taureau (VP I 912), vient toutefois d'être dégagée (janvier 2011) à l'extrémité ouest de la galerie nord du quadrangle nord par les équipes de restaurateurs indiens de l'ASI. Les superstructures des murs de latérite s'étant effondrées à l'intérieur, cette pièce unique gisait en dessous. Sculptée dans un grès doré friable, la sculpture est incomplète et érodée. La face du Taureau est éclatée (seul un fragment du front est conservé) et ses pattes sont brisées. Le rendu du Taureau est un peu raide et ses formes sont plates. La tête, légèrement tournée de côté, regarde du même côté que les divinités. L'animal porte au front un large bandeau orfévri orné en son centre d'un fleuron en losange, noué par une cordelette à pompons qui passe entre la corne et l'oreille gauche. Son cou est paré d'un rang de perles. Les deux divinités sont quant à elles brisées à la taille. Śiva, figuré de face, est assis en aisance royale sur les omoplates de sa monture, tandis qu'Uma est agenouillée sur la croupe, la partie basse du corps vue de profil. La jambe droite de Śiva est repliée, la gauche pend contre la panse du Taureau, la main gauche est posée à plat sur la cuisse. Le court sampot, maintenu par une ceinture lisse, possède une poche latérale plaquée du côté gauche. Un pan latéral presque effacé est visible sur le sarong lisse d'Uma. Cette sculpture pourrait dater de la fin du $x^{\mathrm{e}}$ ou du début $\mathrm{du} \mathrm{XI}^{\mathrm{e}}$ siècle (style de Banteay Srei). Il s'agit à notre connaissance de la seule pièce en ronde-bosse de ce type connue à ce jour. On peut rappeler que le fronton de la fausse porte orientale de la galerie sud du quadrangle nord figure exactement la même iconographie (style du Baphuon).

Un petit buste (tête et bras manquants), trouvé en surface à l'intérieur de la cella du sanctuaire principal de Vat Phu, est exposé au musée du site (VP I 594). En l'absence de toute parure, la pièce est difficile à identifier et à dater. Il pourrait toutefois s'agir d'un buste de Śiva Ardhanarîśvara, dans la mesure où le sein droit, légèrement plus plat que celui de gauche, induit peut-être une forme androgyne. Ce type de pièce, assez rare, appartient surtout au style du Bayon ${ }^{(1)}$.

Peu de linga de type angkorien à triple section ont été retrouvés à Vat Phu. Un exemplaire incomplet, sculpté dans un grès très sonore d'excellente qualité, a été mis au jour en 1991 (VP I 568). Il avait été rejeté (ou placé) à une date indéterminée devant le linteau au sol du templion. Quatre linga fragmentaires viennent de la zone de la source (VP I $566,567,610$ et 612); deux autres sont marqués en «VP», sans autre précision quant à l'endroit de leur découverte (VP I 494, 511). Le linga principal du sanctuaire n'a pas été retrouvé, mais une pièce tripartite d'assez grande taille gît encore au sol dans la sala moderne de la terrasse supérieure. Deux linga tripartites provenant de la région (VP I 260 et 261), sculptés dans un grès très fin (dorite?), sont par ailleurs exposés au musée. Aucun de ces vestiges n'a été retrouvé avec son piédestal d'origine.

Près d'une centaine de petits linga étaient associés au rocher de Khan Mak Houk, situé dans le Mékong, en face du temple de Houay Tomo, à la pointe de l'île de Dong Deng. Sculptés à même le plat du rocher par groupes d'importance variable, ils ont tous été arrachés volontairement à une date indéterminée et jetés dans l'eau aux alentours. Parmi ceux qui ont été retrouvés, vingt-cinq sont présentés au musée de Vat Phu. Ils sont 
en règle générale de petite taille - 5 à $7 \mathrm{~cm}$ de hauteur en moyenne, pour un diamètre équivalent -, mais quelques-uns, de taille un peu supérieure, avoisinent les $15 \mathrm{~cm}$. L'analyse des scènes sculptées sur le rocher indique que celui-ci avait pour fonction de sanctifier les eaux du fleuve ${ }^{61}$. Les linga - supposés par la tradition être au nombre de mille - ornaient le plat du rocher, tandis que de nombreuses scènes vishnouites (sommeil de Vișnu, Vișnu Kūrma, etc.) étaient sculptées en bas-relief sur la face ouest du récif, seule accessible. De même que dans le lit de la rivière de Siem Reap, à Kbeal Spean aux Kulen (Cambodge), ces représentations étaient destinées à transfigurer les eaux du fleuve en celles du Gange. Les reliefs, très érodés, ont subi les mêmes dommages que les lingales visages des divinités ayant eux aussi été arrachés volontairement. D'après le style des parures conservées, ces reliefs peuvent être datés des $\mathrm{XI}^{\mathrm{C}} \mathrm{-X} \mathrm{XI}^{\circ}$ siècles. Une paire de linga et un linga pourvu d'un tenon (KMH I 643) constituaient des pièces rapportées qui venaient s'insérer dans des mortaises taillées sur le plat de la roche ${ }^{62}$. Six d'entre eux -cinq petits (VP I 265 à 269) et un plus grand (VP I 264) - provenant sans conteste de Khan Mak Houk, ont été retrouvés à Vat Phu où ils ont été amenés à une date inconnue.

Un très beau piédestal en bronze ( $15 \mathrm{~cm}$ de côté) accueillant un linga en pierre verte (KMH II 51) a été retrouvé dans l'eau près du rocher. Dans un état de parfaite conservation, il est exposé au musée ${ }^{6.3}$. La couleur verte semble privilégiée à Vat Phu pour de nombreux éléments en pierre en relation avec l'élément liquide. Lors des fouilles effectuées dans la zone de la source (PRAL 1991-1993), nous avions déjà remarqué que plusieurs vestiges - linga, sections de canalisations pour l'acheminement des eaux de la source, dalles, etc. - étaient taillés dans un grès vert clair. La même chose a été observée à Khan Mak Houk avec une paire de linga amovibles sur socle (KMH I 586).

Le mukhalinga (fig. 21) qui était installé dans le gopura sud-est du temple de Houay Tomo (TM I 790) est entré récemment au musée de Vat Phu, avec d'autres pièces du même site (linteaux, somasütra, etc.) ${ }^{64}$. D'une facture particulière, unique en son genre, il était considéré jusqu'à présent comme une pièce préangkorienne, mais pourrait être en fait plus tardif. Au lieu de présenter une petite tête de Śiva sculptée à la base de sa section hémisphérique, comme c'est le cas pour les autres exemples connus, ce mukhalinga montre, à l'extrémité d'un long tenon quadrangulaire en forme d'obélisque aux angles coupés, deux grands visages sur chacune des grandes faces. Ces visages sont flanqués, sur une des faces latérales, d'un linga sur socle en bas-relief. L'autre face latérale, plus étroite et délitée, ne porte pas trace d'un second linga qui aurait fait pendant au premier. Les visages moustachus et barbus sont ceux de Śiva ascète, mais la tête est parée d'une haute coiffe conique ouvragée, dont les motifs végétaux rappellent ceux de l'art cham

61. Santoni \& Hawixbrock 1998 et notice de Chr. Hawixbrock dans le catalogue du musée de Vat Phu (Hawixbrock et al. 2012).

62. Santoni \& Hawixbrock 1998, photo. 9.

63. Cf. la notice de Chr. Hawixbrock et de V. Souksavatdy dans le catalogue du musée de Vat Phu (Hawixbrock et al. 2012). Une pièce similaire, quoique plus petite, avec un linga en quartz laiteux, est exposée au Musée national du Cambodge ( $\left.{ }^{\circ} 3557\right)$. Un autre piédestal à linga (perdu), presque identique à celui de Khan Mak Houk, provenant de la région d'Angkor, est conservé au musée Guimet, nº 18187.

64. Le temple de Houay Tomo est le seul sanctuaire angkorien connu de la province de Champassak qui soit installé sur la rive gauche du Mékong. Situé près de l'embouchure du Houay Tomo, il possède un débarcadère à gradins donnant sur la rivière. Très ruiné et enfoui sous la végétation, il fut partiellement dégagé en 1997-1998 par Oscar Nalesini, qui en a levé le plan. Le site semble avoir connu plusieurs périodes de construction, compte tenu de certains vestiges anciens (céramique, linteaux, candraśălā et somasütra) retrouvés en surface. Les structures en latérite et grès visibles aujourd'hui, remontant au $\mathrm{XI}^{\mathrm{C}}$ siècle au moins. pourraient être implantées sur un temple préangkorien. 
ou ceux de l'art de Dvāravatī ${ }^{65}$. La barbe, ornée de rinceaux sur une face, est cerclée d'un rang de perles, peut-être le rosaire, attribut de Śiva en tant que dieu des ascètes ( $r s i)$. L'iconographie curieuse de cette pièce, sa facture malhabile, ainsi que la forme générale du bloc - peut-être retaillé à une extrémité au vu de la platitude des images suggèrent un réemploi de la pierre qui aurait pu être à l'origine un élément architectural. Le traitement très plat des visages est comparable à celui d'un bas-relief du même type figurant un Śiva ascète moustachu, assis et tenant le rosaire, trouvé au Champa dans la citadelle de Cha-Ban au nord de Binh Dinh ${ }^{66}$. Ces données incitent à donner une date tardive pour l'exécution de cette sculpture. Plusieurs inscriptions de la région, dont la stèle digraphique (K. 362) datée de 889 qui a été retrouvée à Houay Tomo, mentionnent l'existence d'ermitages (äsrama) shivaïtes dans les montagnes proches du sanctuaire de Vat Phu. On peut se demander si ce mukhalinga n'a pas été déplacé d'un sanctuaire rupestre, ce qui pourrait être une autre explication de son iconographie singulière.

\section{La statuaire vishnouite}

Nous avons déjà mentionné plus haut que l'inscription K. 366 trouvée dans l'avant-corps hypostyle du sanctuaire principal de Vat Phu évoquait l'érection d'images de Viṣnu au XII" siècle. En dehors de sa représentation sur la roche qui figure en bas-relief la Trimürti, peu d'images en pierre du dieu, pour la période angkorienne, ont pourtant été découvertes. Parmi les rondes-bosses, on ne peut en citer que deux, appartenant apparemment au style du Bayon. La première, aujourd'hui disparue, est le Viṣnu debout à quatre bras que H. Parmentier et G. Trouvé ont vu dans l'avant-corps hypostyle du sanctuaire, et qui fut photographié plus tard par André Louis Lochard (fig. 22) ${ }^{67}$. Le second est un buste qui est exposé au musée de Vientiane.

L'iconographie du sanctuaire central de Vat Phu (style du Baphuon), comme celle de nombreux autres temples shivaïtes angkoriens, fait cependant largement référence à Viṣnu sur les frontons et les linteaux. Le dieu y est figuré debout sur Garuḍa. Son avatar Krșna est représenté deux fois (écartelant un démon et le serpent Kāliya). Le sommeil de Vișnu et le barattage de la mer de lait sont également figurés, ainsi que des épisodes du Ràmàvana.

Un Vișnu sur Garuḍa (VP I 1) datant de la fin du XI"-début du XII ${ }^{\mathrm{e}}$ siècle, présenté au musée du site, était placé sur la terrasse supérieure de Vat Phu. Il était complet en 1957 lorsque H. Marchal l'a photographié ${ }^{68}$. La partie supérieure du corps du dieu a depuis disparu, ainsi que l'extrémité des ailes de sa monture. Une ébauche de Garuḍa de 1,87 m de haut (VP I 21 ) est conservée dans la réserve de Champassak.

Deux petits Viṣnu en bronze ont été retrouvés sous l'abri sous roche situé à l'arrière du templion (PRAL, 1992). Le dieu est représenté debout et possède quatre bras. La première image (VP II 54), du style du Baphuon, est complète et a conservé tous ses attributs : le disque en main supérieure droite, la conque en main supérieure gauche, la Terre en main inférieure droite et un attribut long et fin du type corne (la massue ?) en main inférieure gauche. La seconde image (VP II 57), du style d'Angkor Vat, ne tient avec

65. Cf. la haute coifle d'une tête de deva en stuc provenant de Prah Pathom ou de Neun Hin en Thaïlande, cliché EFEO de 1939 (TIIA23736).

66. Chronique du BEFEO 1, fig. 75, p. 412.

67. Clichés pris entre 1914 et 1933.

68. Marchal 1957, p. 28. 
la même disposition que trois de ces objets, puisque la main inférieure droite est perdue. Les statuettes étaient accompagnées d'une petite divinité féminine non identifiable en l'absence de ses attributs (VP II 55). Elles sont présentées au musée de Vat Phu avec la partie basse d'un corps de divinité masculine en bronze (VP II 53), de taille supérieure (35 cm de haut de la base à la taille). Celle-ci a été retrouvée coincée sous une grande dalle en grès vert tombée à l'intérieur du templion. La partie supérieure du corps, restée accessible suite à cet accident, a été arrachée à date ancienne. La pièce témoigne d'une très grande maîtrise technique. Un soin particulier a été apporté à l'ornementation du sampot et des parures, notamment la ceinture ornée de pendeloques en fer de lance.

\section{Brahmā}

Brahmā est peu représenté. En dehors de sa figuration sur le rocher de la Trimürti, deux images seulement sont connues. La première, en pierre, est très abîmée (VP I 248). Le dieu est sculpté en bas-relief, assis sur un lotus, avec trois têtes et quatre bras. La face postérieure du bloc montre un arrachement qui laisse penser que la sculpture a été détachée d'une représentation rupestre. Elle pourrait appartenir à un ensemble disparu figurant le sommeil de Viṣnu. La seconde est une petite tête en bronze doré à quatre visages $\left(\mathrm{XI}^{\mathrm{e}}-\mathrm{XII}^{\mathfrak{e}}\right.$ siècle), retrouvée hors contexte dans la zone de la source (VP II 58).

\section{Autres divinités}

Une divinité bossue coiffée d'un diadème noué à l'arrière (VP I 47), au visage scié intentionnellement, est conservée au dépôt de Champassak. On rencontre essentiellement ce type de représentation dans l'art du Bayon. Il est possible qu'il s'agisse d'une figuration de Kubera. L'ébauche d'une divinité bossue d'assez grande taille $(83 \mathrm{~cm}$ de haut), en position assise avec un genou relevé, est présentée par ailleurs à l'entrée du musée du site (VP I 399).

Les quelques pièces retrouvées qui appartiennent au style du Bayon (fin XII'-début XIII" siècle) - comprenant les deux grands dvārapāla installés sous les édicules, de part et d'autre de l'allée axiale qui mène à la terrasse supérieure - témoignent de l'attention que porta Jayavarman VII à Vat Phu. L'allée couverte qui clôturait le côté ouest de la terrasse supérieure, à l'arrière du sanctuaire principal, est probablement un ajout effectué durant son règne. Des fragments pourraient appartenir à des Avalokiteśvara de cette période, parmi lesquels trois mains - l'une tenant le rosaire (HNS I 525, réserve de Vat Phu) et les deux autres le flacon (musée du site [VP I 518] et musée de Paksé). Une statuette en grès de Buddha assis en méditation sur le nāga) est caractéristique du style (VP I 426, partie basse seule conservée). On sait que les hôpitaux de Jayavarman VII étaient placés sous la protection du Bodhisattva compatissant. Aucune statue n'a été repérée à Thao Tao, mais le monument, très ruiné, est à peine dégagé.

\section{Les objets en métal}

Le manche de préhension en bronze d'une clochette rituelle (VP II 56, corps disparu) orné de deux têtes de dragons affrontés a été trouvé à l'arrière du templion avec les statuettes en bronze susmentionnées. Il pourrait dater de la fin de l'époque angkorienne.

Un petit reliquaire avec couvercle en forme d'étui circulaire, constitué d'une feuille d'or enroulée, a été trouvé sous le mur oriental du templion. Il enfermait deux petites pierres jaunes polies (VP III 65). Un second reliquaire (VP III 64), fait de trois feuilles d'or repliées en cornet, contenait une pierre bleu clair polie, peut-être un saphir. 
Une réduction en argent de tour-sanctuaire (MK II 52) a été retrouvée dans le Mékong, prise dans le filet d'un pêcheur aux abords de la ville ancienne (fig. 23). Cet ouvrage de très belle facture est à notre connaissance, parmi les exemples connus du même type, celui qui comporte la plus grande richesse de détails. Seul le premier faux étage est conservé, la partie supérieure de la tour est perdue (hauteur : $20 \mathrm{~cm}$ ). La miniature reprend les caractéristiques architecturales des tours-sanctuaires angkoriennes en pierre. De plan carré, surélevée sur une base ajourée à douze pieds ouvragés, elle s'ouvre sur les quatre côtés par une porte au seuil décoré de pétales de lotus. Les frontons de l'étage et du faux étage sont ornés de motifs végétaux, une seule des quatre antéfixes d'angle étant conservée. La tour contient un piédestal mouluré à bec d'écoulement, pourvu de deux pics soudés en vis-à-vis sur le bord supérieur, dont la fonction n'est pas déterminée. Percé d'un trou circulaire, il devait accueillir un linga. Un soin tout particulier a été apporté à la confection du piédestal. Reprenant les caractéristiques des véritables piédestaux en pierre, un cube à dépôt de fondation a été installé à l'intérieur, dans l'axe de l'ouverture prévue pour recevoir la base de l'idole. Il est pourvu, sur sa face supérieure, de huit alvéoles circulaires formant un cercle autour de la neuvième alvéole, centrale. Une petite plaque amovible carrée faisait office de couvercle, gravé sur sa face supérieure d'un lotus épanoui, cantonné de crosses végétales. La complexité du dispositif indique qu'une cérémonie de consécration a dû être pratiquée, probablement lors de la mise en place des dépôts de fondation et de l'idole.

Deux bronzes de la fin de l'époque angkorienne, provenant de Vat Phu, ont été transférés dans des musées étrangers. Un manche de miroir inscrit orné d'un Śiva dansant datant du règne de Jayavarman VII est conservé au musée Guimet ${ }^{69}$. Un bel anneau de litière (fig. 24) était entré au musée Louis Finot à Hanoi ( $n^{\circ}$ I 25377), aujourd'hui musée d'histoire du Vietnam. Il faut également rappeler l'about de timon de char en bronze terminé par une tête de nāga tricéphale, aujourd'hui disparu, qui faisait partie de la collection Boun Oum. Un objet comparable est exposé au Musée national du Cambodge ( $\mathrm{n}^{\circ}$ d'inv. $5737)^{70}$, et deux autres sont au musée Guimet (MG 18888 et 18889) ${ }^{71}$.

Nous venons d'apprendre la découverte par l'équipe indienne de l'ASI d'une bague en or enfermée avec un fossile de gastéropode dans une petite boite circulaire à couvercle, en porcelaine blanche sans décor, d'origine chinoise. Elle a été mise au jour sous des blocs effondrés à l'angle extérieur nord-est du porche de la galerie nord du quadrangle nord. L'anneau élargi sur la face supérieure en amande est serti d'une pierre noire ovale polie maintenue par quatre griffes. Le décor au granulé, circonscrit autour de la pierre, couvre tout l'espace en amande. Elle appartient à la période angkorienne et peut être datée des $\mathrm{X}^{\mathrm{e}}-\mathrm{XII}$ siècles environ.

\section{La céramique utilitaire}

Près d'une dizaine de grandes céramiques angkoriennes faisaient partie de la collection du prince Boun Oum. Les mieux conservées sont exposées au musée de Vat Phu, les autres ont été déplacées au musée de Paksé. Les vases balustres et les jarres à couverte grise ou brune, avec ou sans glaçure, sont typiques de la fin de l'époque angkorienne. L'origine précise de toutes ces pièces est perdue.

69. Baptiste \& Zéphir 2008. p. 372-373. La provenance précise de l'objet (n“ EO 801) est inconnuc.

70. Dalsheimer 2001, p. 279, photo 157.

71. Baptiste \& 7éphir 2008. p. 358-360. 
Un fragment de vase zoomorphe en forme de tête d'éléphant (BNS VI 126), plusieurs vases lenticulaires et des pots à couvercle complètent la série des céramiques exposées. Elles ont été choisies parmi les pièces les mieux conservées. Beaucoup ont été trouvées lors de prospections menées dans la zone située au pied de la montagne, au sud de Vat Phu, et autour du temple de Nang Sida. Nous avons déjà indiqué que des établissements urbains avaient pu se rapprocher de Vat Phu à l'époque angkorienne, bien qu'aucun n'ait pu être identifié avec certitude. C'est ce que suggèrent, parmi d'autres indices, les collectes de matériel céramique effectuées dans la région. Dans la ville ancienne, cependant, de la céramique angkorienne a été mise au jour en nombre suffisant pour attester une réoccupation du lieu.

Au musée de Paksé sont présentées des céramiques (vases lenticulaires, pots à couvercle) trouvées autour de la chapelle d'hôpital de Thao Tao.

\section{Les collections d'art laotien}

\section{Les pièces bouddhiques}

Les Buddha de la collection du prince Boun Oum constituent une grande partie des pièces d'art lao du musée de Vat Phu. Postérieurs de plusieurs siècles aux pièces khmères, ils auraient d'abord été conservés au Vat Thong - monastère où sont édifiés les that de la famille princière de Champassak - puis seraient entrés en possession de la princesse de Champassak.

À côté de quelques belles images originales - comme le Buddha en grès stuqué attestant la Terre, dont les boucles de cheveux sont traitées en pointe (VP VI 14, $X I X^{C}$ siècle ?) - d'autres semblent être des copies de pièces relevant d'époques plus anciennes. Certaines de ces statues sont en pierre (stéatite ?) recouverte de bronzine (par exemple VP II 9). Trois Buddha debout en bronze, de mauvaise qualité, proviennent sans le moindre doute du même moule (VP II 3, 4 et 35) : seule la position des mains, rapportées, varie. Ils sont figurés en costume monastique, le drapé du vêtement s'inspirant directement de l'art de Dvāravatī. Il en est de même d'autres Buddha assis en méditation ou prenant la Terre à témoin. Quatre statuettes formant deux paires, deux Buddha assis à l'occidentale (VP I 344 et 345) et deux Buddha assis prenant la Terre à témoin (VP I 343 et 346), sont particulièrement curieuses (fig. 25). Elles ont été réalisées en latérite (la technique de façonnage fait penser au moulage) et recouvertes d'une laque noire qu'on a dorée ${ }^{72}$. Elles sont difficilement datables, mais rappellent également l'art de Dvāravatī.

Un Buddhapāda en pierre d'origine inconnue (VP I 486), incomplet et brisé en plusieurs fragments, est conservé dans la réserve de Champassak.

Les Buddha en bois sont, en règle générale, très récents et ne présentent pas d'intérêt particulier, la plupart étant des statuettes aux formes frustes. Parmi les exceptions, on note un beau Buddha debout en bois laqué et doré (VP V 1), de taille presque humaine $(131 \mathrm{~cm}$ de haut), qui semble dater du XIX siècle. Vêtu du costume monastique, il est dans l'attitude dite " appelant la pluie », les deux bras ballants étant écartés du corps et prolongés par des mains tendues aux doigts recourbés. L'image doit être exposée après restauration.

Les plus belles pièces des collections laotiennes conservées au musée de Vat Phu sont en fait celles dont on connaît l'origine précise, car elles ont été retrouvées récemment.

72. D’après Pierre Pichard, mouler aussi finement de la latérite doit s’avérer très difficile, voire impossible (communication personnelle). 
Elles proviennent d'une part de l'abri sous roche situé à l'arrière du templion, d'autre part du dépôt de fondation du monastère de Houay Sa Houa 1 (HSH1) - au nord de l'embouchure du petit cours d'eau - qui a été révélé par un effondrement de la berge du fleuve et a donné lieu à une fouille de sauvetage (PRAL 1992).

Huit des Buddha laotiens qui accompagnaient les bronzes angkoriens derrière le templion sont exposés à Vat Phu (VP II 73, 81, 82, 84, 85, 96, 106 et 107). On peut également citer un Kaccāyana en bronze (VP II 80) qui, grâce à une dédicace d'une ligne gravée sur son socle, peut être daté du XvII ${ }^{\circ}$ siècle (fig. 26). Ces pièces avaient été installées là par des pèlerins bouddhiques. De très nombreuses Saintes Empreintes figurant le Buddha assis, prenant la Terre à témoin ou en méditation, accompagnaient ces statuettes. Trois sont en or (VP III 55, 57, 58), d'autres sont en plomb (?) recouvertes d'un apprêt blanc, mais on en compte également plusieurs centaines en résine végétale (keson dok mai). En certains endroits, elles pavaient littéralement le sol de l'abri sous roche.

Près de trois cent statuettes de Buddha - dont quatre sont en bronze (HSH Il 59, 63, 67,69 ) et les autres en résine végétale recouvertes de feuilles d'or ou d'argent travaillées au repoussé - proviennent du dépôt de fondation du monastère bouddhique de HSH1, datant du XIX ${ }^{e}$ siècle. La cache en pierre qui les contenait était faite de dalles en grès en réemploi appartenant probablement à la période préangkorienne. Quinze de ces images sont exposées au musée de Vat Phu. La plupart figurent le Buddha assis sur de très hauts trônes gravés de motifs végétaux ou géométriques (fig. 27). Les müdra sont peu variés, la prise de la Terre à témoin domine, suivie par la méditation. Celui du don est représenté par quelques exemples. Un grand nombre des statuettes votives en keson dok mai possèdent une dédicace. Celle-ci indique le nom du donateur, l'objet du don et la date. Les dédicaces permettent de dater les plus anciennes de ces images du XVII siècle et les plus récentes du début du XIX ${ }^{\mathbb{E}}$ siècle $^{73}$. Des Saintes Empreintes formées d'une plaque d'or ou d'argent embouti font partie des découvertes ; deux sont exposées au musée du site. Un très bel exemple double (ex HSH I 92-35), à l'âme en résine végétale et pourvu sous sa base d'un petit jeton en or, est exposé au musée Kaisone de Vientiane. Quatre images de Kaccāyana, dont deux en bronze (HSH II 65 et 70) et deux en alliage d'argent (HSH III 14 et 15), complétaient ce dépôt sacré.

D'autres statuettes de Buddha en keson dok mai du même type, probablement légèrement plus tardives, ont été retrouvées à l'intérieur d'une jarre enterrée au pied de l'une des tours en brique construites sur la terrasse intermédiaire du temple de Vat Phu.

Plusieurs bai-sema de grande taille appartenant à la collection Boun Oum, ornés de la représentation du stīpa élancé caractéristique des modèles tardifs ( $\mathrm{XIX}^{\mathbb{C}}$ siècle), complètent ces collections bouddhiques d'art lao.

\section{Les pièces particulières de la collection Boun Oum}

La collection Boun Oum est intéressante à plus d'un titre, tant par son étrangeté que par les questions qu'elle suscite. Quelque 200 pièces - en pierre, métal et bois constituent ce fonds assez hétéroclite. M. Giteau, lors de sa rencontre avec le prince de Champassak, semble s'être intéressée seulement à trois pièces authentiquement khmères aujourd 'hui disparues - et s'être dispensée de commentaires sur le reste de sa collection. Est-ce à dire que seuls ces trois objets ont présenté un intérêt à ses yeux ? Cela est probable, vu les caractéristiques hors normes que présentent les sculptures conservées. On peut toutefois supposer que celles qui sont aujourd'hui visibles ne constituent finalement

73. Cf. Hawixbrock 2000 et les notices de Chr. Hawixbrock dans le catalogue du musée de Vat Phu (Hawixbrock et al. 2012). Une sélection des plus belles de ces statuettes est exposée au musée de Vat Phu. 
qu'une partie, plus ou moins importante, de la collection que le prince avait rassemblée. Parmi les pièces particulières que recèlent les dépôts, on peut distinguer deux ensembles.

\section{Les pièces "factices"}

L'examen attentif des quelques sculptures de style khmer qui sont restées à Champassak, toutes en parfait état, montre qu'il s'agit de copies, voire de faux. Ainsi en est-il d'une divinité féminine (VP I 239) et d'un Avalokiteśvara (VP I 178), dont la facture rappelle des images préangkoriennes (fig. 28$)^{74}$. À ces pièces, il faut ajouter deux plaques décoratives en grès : la première figure la naissance du Buddha (VP I 235); la seconde donne une représentation dans le style angkorien de Viṣnu monté sur Garuḍa (VP I 177), thème qui est repris pour une statuette en bronze (VP II 1), fausse également. Certaines des pièces bouddhiques que nous avons mentionnées plus haut, copies inspirées du style de Dvāravatī (VP II 3, 4, 35), pourront être rattachées à cet ensemble.

\section{Les pièces appartenant à un " art local tardif" »}

Sur les 129 sculptures en pierre (grès et pierre noire non identifiée) que totalise la collection Boun Oum, 121 constituent un groupe que Bruno Dagens a qualifié d'art local $\operatorname{tardif}^{75}$. Dans la mesure où elles représentent une part non négligeable des collections de Vat Phu, il nous a paru nécessaire de leur consacrer un chapitre de cette étude.

La majorité de ces pièces s'inspirent de l'art khmer ou cham, tant d'un point de vue iconographique que stylistique. Elles figurent des personnages et des scènes du bouddhisme (Buddha, bodhisattva, déesse Terre) et de l'hindouisme (Śiva dansant, Gaṇeśa, Viṣnu couché ou émergeant d'une conque, Brahmā, divinités féminines), mais leur traitement a souvent donné lieu à des réinterprétations, pour ne pas parler d'erreurs : inversion des gestes du Buddha, confusion des attributs des dieux, etc. Hanuman est représenté dans diverses attitudes, par exemple enserrant la montagne ou emportant Sītā dans ses bras. Parmi les figures moins personnalisées, on reconnaît un ascète shivaïte, des dvārapāla et une apsara.

D'autres pièces, moins nombreuses, figurent des musiciens ou illustrent des légendes locales encore connues aujourd'hui, telles celles de Nang Sida ${ }^{76}$ ou de la dame Malong (une jeune fille séduite et abandonnée avec son enfant nouveau-né).

Une série de sculptures aux formes plus brutes représentent de petits orants stylisés. Leur corps ( $30 \mathrm{~cm}$ de haut en moyenne) se résume à un cylindre au sommet plus ou moins conique figurant le crâne ; seuls le visage et les mains, en relief, sont indiqués. Il existe également quelques représentations animales, comme des éléphants, une mangouste enserrant un serpent et un crocodile couché d'assez belle facture (VP I 358).

Aucune des pièces de cet ensemble n'est exposée au musée de Vat Phu, mais elles méritent certainement d'être présentées dans un autre lieu, dédié à cet art local plus récent. Le musée de Paksé en montre quelques-unes, dont des orants, un joueur de flûte et un personnage féminin. Il n'existe pas, à notre connaissance, de sculptures de ce type connues hors de la province de Champassak. Leur origine reste mystérieuse : il n'est

74. Dans le cas de l'Avalokiteśvara, il doit s'agir de la statue considérée comme préangkorienne décrite par B. Dagens en 1986 (p. 9). Valérie Zaleski, dans la note qu elle a rédigée pour la base de données, montre que cette image est directement inspirée d'une pièce connue et exposée en Thaïlande.

75. Dagens 1986, p. 9.

76. Voir détails de la légende dans Aymonier 1901, vol. 2, p. 172. 
pas impossible que ce soit le prince Boun Oum lui-même qui les ait commanditées ; il faudrait sinon supposer qu'il se soit rendu acquéreur d'un lot. La facture de ces pièces, le plus souvent malhabile, met en évidence l'inexpérience des sculpteurs et laisse supposer une source commune, un même lieu de production, voire un unique atelier. On peut supposer qu'elles ont été taillées dans la région, puisque certaines font référence à des légendes locales. Le reste de la collection du prince Boun Oum est composé de pièces hétéroclites : jarres chinoises et vietnamiennes récentes, certaines en porcelaine au décor bleu sur blanc, décorées de dragons ou de scènes florales ; céramiques à glaçure caramel au décor moulé puis appliqué ; petit mobilier en cuivre ou en bronze contemporain (plateaux, théières, marmites, gongs); etc.

\section{Conclusion}

L'étude des témoignages archéologiques de la province de Champassak, en particulier ceux qui ont été collectés autour de Vat Phu et que conservent aujourd'hui le musée et les réserves du site, prouvent une occupation longue et continue de la région par des sociétés touchées par l'indianisation. Dès les débuts de la période préangkorienne, les productions artistiques khmères du Sud-Laos se caractérisent par une maîtrise technique et une singularité très forte sur le plan stylistique, comme en témoignent les nombreux vestiges qui ont été retrouvés. Ce particularisme régional est avant tout visible dans les éléments lapidaires qui révèlent une forte pratique des cultes hindouistes, mais également la marque de traditions bouddhiques évoluées. L'étude des styles montre, en plus des éléments proprement khmers, une combinaison d'influences venues des régions voisines, qu'il s'agisse de la culture dite de Dvāravatī, à l'ouest, ou celle du pays cham, à l'est. Il est manifeste que le sanctuaire de Vat Phu a été longtemps le point de rencontre entre ces différentes aires culturelles et politiques. Ce rôle est dû à sa situation géographique exceptionnelle, du fait, d'une part, de l'adéquation entre le caractère physique du site et sa dimension proprement religieuse (présence du Lingaparvata) et, d'autre part, de sa position en bordure du Mékong. On ne saurait en effet trop insister sur l'importance de cet axe de communication privilégié que renforçait sur ses deux rives, en amont comme en aval, un réseau de rivières aussi importantes que la Sé Mun et la Sékong, elles-mêmes gonflées par plusieurs gros affluents.

Les collections archéologiques de Vat Phu témoignent bien, par le nombre, la diversité, la taille et la qualité artistique des pièces - que ce soit à l'époque préangkorienne ou angkorienne - de la richesse économique de cette région durant une longue période, et au-delà de la puissance particulière dont furent investies les autorités qui la contrôlèrent.

Si nous connaissons le tracé de la route khmère qui, à l'époque angkorienne (dès le début du $x^{2}$ siècle ?), relia le sanctuaire de Vat Phu à Angkor, aucune route terrestre plus ancienne n'a pu être déterminée pour l'instant. Les plus riches des sites préangkoriens situés dans le district de Mounlapamok sont tous construits en bordure du Mékong. Une route perpendiculaire au fleuve se dessine sur quelques kilomètres à peine, matérialisée par le relevé de l'emplacement des sites repérés dans l'intérieur des terres ${ }^{77}$, mais cette route ne semble guère aller au-delà d'un territoire probablement géré par les sites du bord du Mékong. Lorsque Mahendravarman, l'un des premiers grands rois fondateur de l'empire khmer (fin du ví siècle), part de Vat Phu pour conquérir à l'ouest des territoires, avant de se tourner vers le sud et de fonder Sambor Prei Kuk au Cambodge, il marque son avancée par des inscriptions dont plusieurs sont situées à proximité de la rivière Sé Mun. Il est donc possible qu'à cette époque, ce soient surtout les voies de communication 
fluviales qui ont été privilégiées. Côté ouest, vers le Champa, il n'est pas impossible que des passes aient été utilisées dans la montagne pour rejoindre les grands sites chams tels que My Son, mais ces régions sont encore insuffisamment prospectées pour qu'on puisse l'affirmer avec certitude. Si nombre de données archéologiques précises nous manquent cncore, ccttc première réflexion sur les collections réunies à Vat Phu confirme l'importance primordiale de cette région pour la compréhension de la naissance du monde khmer ancien.

\section{BIBLIOGRAPHIE}

AYMONII:R, Étienne

1901 Le Cambodge 2 : les provinces siamoises, Paris, Ernest Leroux.

BAPTISTL, Pierre

2005 "Les piédestaux et les soubassements dans l'art cham hindou: une spécificité ? ", in Trésors d'art du Vietnam, P. Baptiste \& T. Zéphyr (éds.), Paris, musée Guimet/RMN, p. 109-121.

BAPTISTE, Pierre \& ZíPHIR, Thierry

2008 Les collections khmères du musée Guimet, Paris, musée Guimet/RMN.

BAptiste, Pierre \& Zi:PHIR, Thierry (éds.)

2005 Trésors d'art du Vietnam, la sculpture du Champa, v゙-vr' siècle, Paris, musée Guimet/RMN.

2009 Dvāravatī. Aux sources du bouddhisme en Thaïlande, Paris, musée Guimet/ RMN.

BI:NISTI, Mireille

1974 "Recherches sur le premier art khmer : 6. Linteaux inédits et linteaux méconnus », Arts asiatiques 30, p. 131-172.

BoISSELLII:R, Jean

1955 La statuaire khmère et son évolution, Saigon, EFEO.

1966 Le Cambodge, Paris, Picard.

Brown, Robert L.

1996 The Dvaravati Wheels of the Law and the Indianization of South East Asia, Leiden, E. J. Brill.

C(:DĖs, George

1953 Inscriptions du Cambodge, vol. 5, Paris, EFEO.

1956 «Études cambodgiennes, XL: Nouvelles données sur les origines du royaume khmer. La stèle de Vat Luang Kau près de Vat Phu », BEFEO 48, p. 208-220.

Colthau, Geneviève

1988 Mémoires du Laos, Paris, Seghers.

ClCARZI, Mauro \& ZOlfese, Patrizia

1998 «An attempt to inventory khmer monumental remains through geomagnetic modelling : the ancient city of Wat Phu ", in P.-Y. Manguin (éd.), Southeast Asian Archaeology 1994, Center For South-East Asian Studies, University of Hull 1, vol. 2, p. 27-48.

DAGENS, Bruno

1986 Préservation des monuments du Vat Phu, Paris, rapport de mission Unesco.

DALSHFIMER, Nadine

2001 L'art du Cambodge ancien. Les collections khmères du Musée national de Phnom Penh, Paris, EFEO/Magellan \& Cie. 
Gitenu, Madeleine

1969 Laos, Étude de collection d'art bouddhique, Paris, rapport de mission Unesco.

2001 Art et archéologie du Laos, Paris, Picard.

HAwIXBrock, Christine

2000 «L'art du métal au Laos », BEFEO 87/1, p. 109-124.

HawIXBROCK, Christine \& SANTONI, Marielle

1999 «Laos. Prospections 1999 au sud de Vat Phou (province de Champassak) : du Houay Khamouanne à la frontière cambodgienne », BEFEO 86, p. 394-405.

Hawixbrock, Christine, Jacquis, Claude, Santoni, Marielle, Souksavatdy, Viengkèo \& ZALESKY, Valérie

2012 Collections du musée de Vat Phu, Vientiane, département du Patrimoine mondial de Vat Phu, Champassak.

JEssup, Helen. I. \& Zi:PHir, Thierry (éd.)

1997 Angkor ou dix siècles d'art khmer, Paris, RMN.

Ll: BonHeUR, Albert

1988 «L'architecture pré-angkorienne en Thaïlande et au Laos », in La Thä̈lande, des débuts de son histoire jusqu'au $x l^{*}$ siècle, premier symposium francothaï, 18-24 juillet 1988, Bangkok, université de Silpakorn.

LinTINGRE, Pierre

1972 «Légendes du Sud-Laos », Bulletin des Amis du Rovaume lao 7-8, p. 213-225.

1974 «À la recherche du sanctuaire préangkorien de Vat Phou », Société française d'histoire d'outre-mer 225, p. 507-521.

LUNi:T DE LAJONQUifRF, Étienne

1907 Inventaire descriptif des monuments du Cambodge 2, Paris, Ernest Leroux, p. 66-89.

MAnguin, Pierre-Yves \& Dalshimimer, Nadine

1998 «Viṣnu mitrés et réseaux marchands en Asie du Sud-Est : nouvelles données archéologiques sur le $1^{\text {er }}$ millénaire ap. J.-C. », BEFEO 85, p. 87-123.

MAlleret, Louis

1969 «Bossus et Nains dans la sculpture en Extrême-Orient », Arts asiatiques 20, p. 121-133.

MARCIIAL, Henri

1957 Le temple de Vat Phou, province de Champassak, Saigon, éditions du Département des cultes du gouvernement royal du Laos.

Na Cinmpassak, Doan

1972 «Un ensemble khmer inconnu, Vat Phu », L'CEil 212-213, p. 19-22.

NALI:SINI, Oscar

2000 "The sanctuary of Huei Thamo and the historical problems raised by its survey ", in Southeast Asian Archeology 1998: Proceedings of the 7th International Conference of the European Association of Southeast Asian Archeologists, Berlin, 31 August-4 September 1998, W. Lobo \& S. Remainn (eds.), Hull/Berlin, Center for Southeast Asian Studies, University of Hull/ Museum für Völkerkunde, p. 123-138. 
Parmentifer, Henri

1914 «Le temple de Vat Phu », BEFEO 14/2, p. 1-31.

1927 L'art khmer primitif, 2 vol., Paris, EFEO.

PfEIFFER, Georges

1975 «Laos. Mise en valeur de sites et monuments historiques et développement du tourisme culturel », juin-juillet 1974, Paris, rapport Unesco.

Pottier, Christophe

1994 «Éléments de couverture mis au jour au Prasat Phanom Wan », Recherches nouvelles sur le Cambodge, Paris, EFEO, p. 297-313.

Rungot Thamrungrueang

2009 "L'image du Buddha sur Phanasbodi », in Dvāravatī. Aux sources du bouddhisme en Thaïlande, P. Baptiste \& T. Zéphyr (éds.). Paris, musée Guimet/RMN, p. 83-87.

SANTONi, Marielle

1998 «Fouille d'un monument préangkorien dans la ville ancienne associée à Vat Phou (province de Champassak, Laos "), in P.-Y. Manguin (éd.) Southeast Asian Archaeology 1994, vol. 2, Hull, Center For South-East Asian Studies, University of Hull 1, p. 1-20.

2008 «La Mission archéologique française et le Vat Phu : recherches sur un site exceptionnel du patrimoine historique du Laos », in Y. Goudineau \& M. Lorrillard (éds.), Recherches nouvelles sur le Laos, Étude thématique $\mathrm{n}^{\circ}$ 18, Vientiane/Paris, EFEO, p. 81-112.

Santoni, Marielle \& Hawixbrock, Christine

1998 «Laos. Fouilles et prospections dans la région de Vat Phu (Province de Champassak, sud du Laos) ", BEFEO 85, p. 387-405.

Santoni, Marielle, Souksavatdy, Viengkèo, Defente, Denis, Hawixbrock, Christine,

Liger, Jean-Claude \& ZOLESE, Patrizia

1991 «Approche archéologique de l'histoire du Laos : l'exemple de Vat Phou », Second symposium franco-thai : récentes recherches en archéologie en Thaïlande (9-11 décembre), Bangkok, université de Silapakorn, p. 194-215.

SAntoni, Marielle, Souksavatdy, Viengkèo, Defente, Denis, Hawixbrock, Christine \& LIGER, Jean-Claude

1997 «Excavations at Champassak and Wat Phu (Southern Laos)» in R. Ciarla \& F. Rispoli (eds.), Southeast Asian Archaeology 1992 (Proceedings of the Fourth International Conference of the South-East Asian Archaeologists), Roma, Is.I.A.O., p. 233-263.

TROLVÉ, Georges

1932 Rapport de la conservation d'Angkor (RCA), document non publié. 


\section{ILLUSTRATIONS}

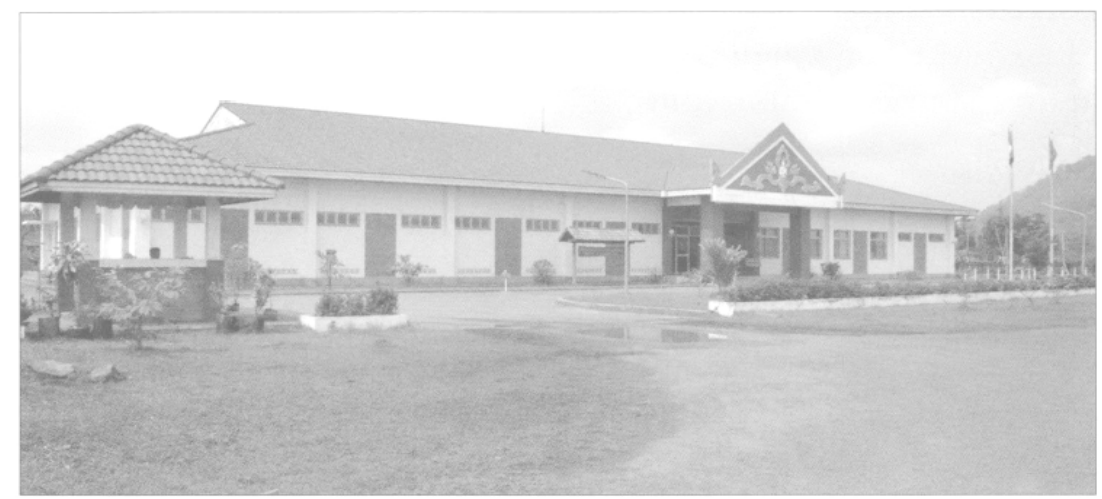

Fig. 1 : musée de Vat Phu.

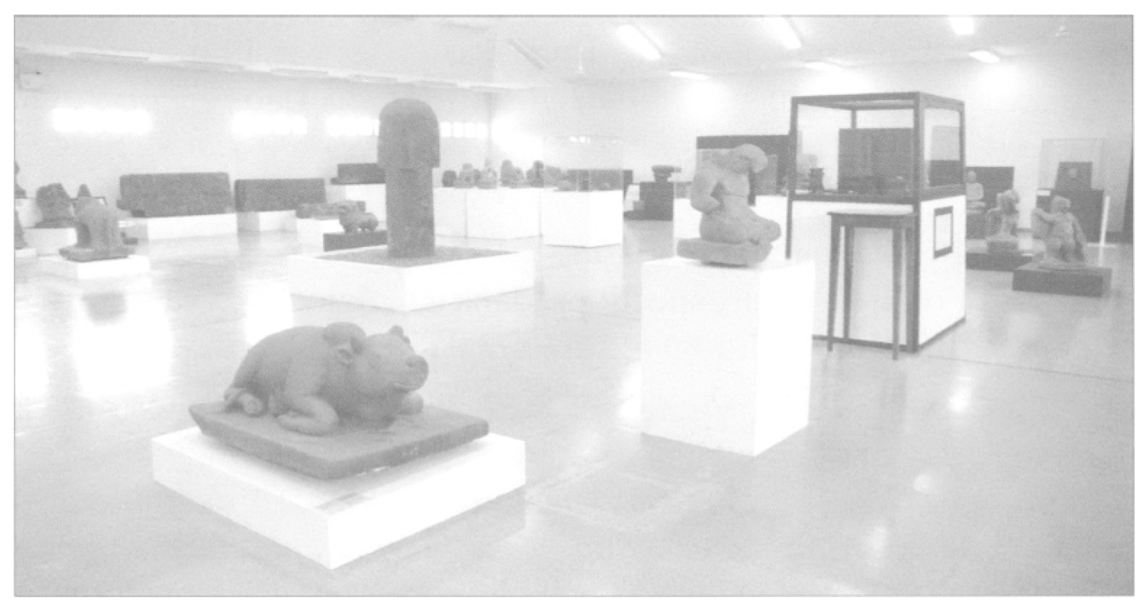

Fig. 2 : salle d'exposition du musée de Vat Phu.

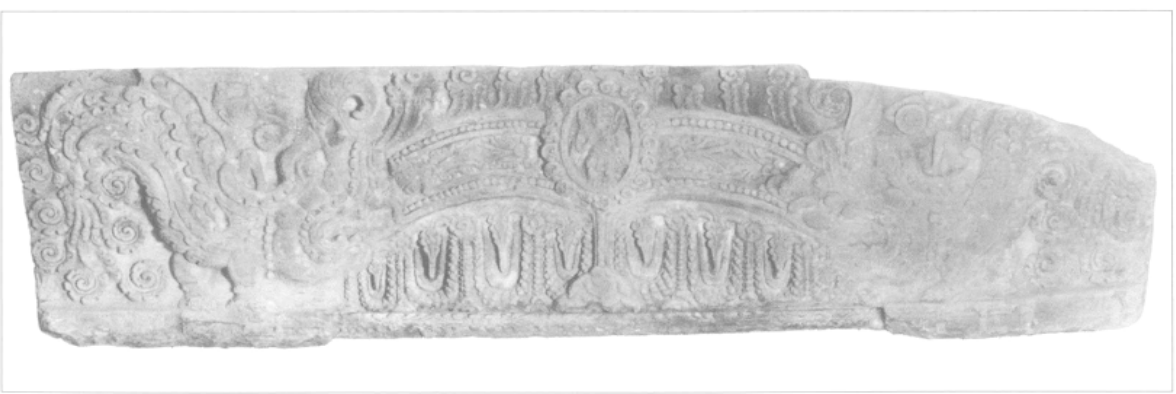

Fig. 3 : linteau préangkorien de Vat Luang Kau (VP I 419 ). 


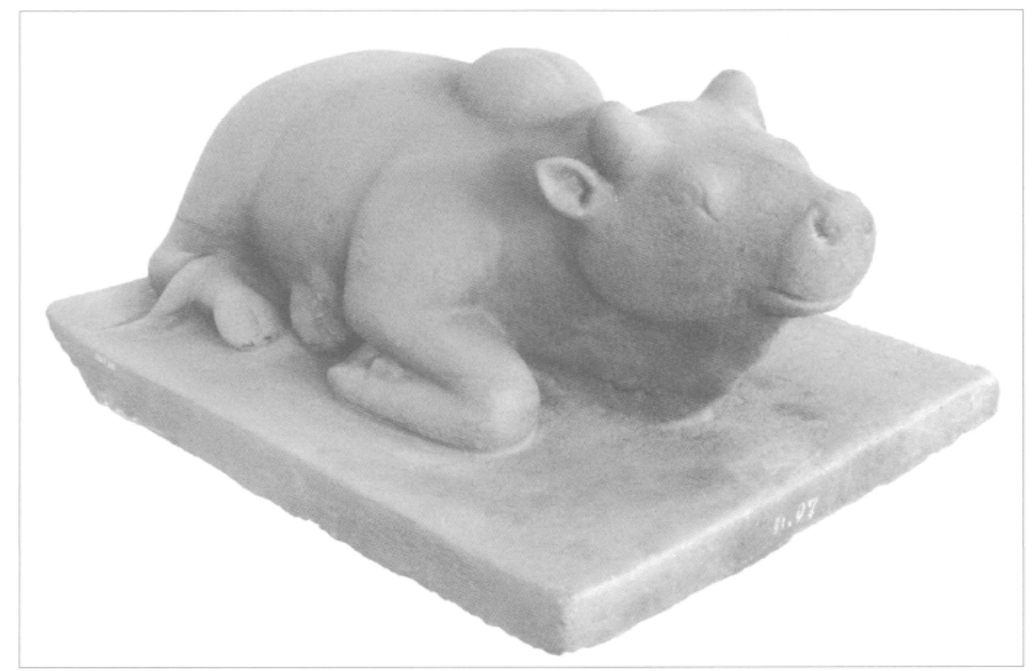

Fig. 4 : Taureau de Vat Luang Kau (VP I 369).

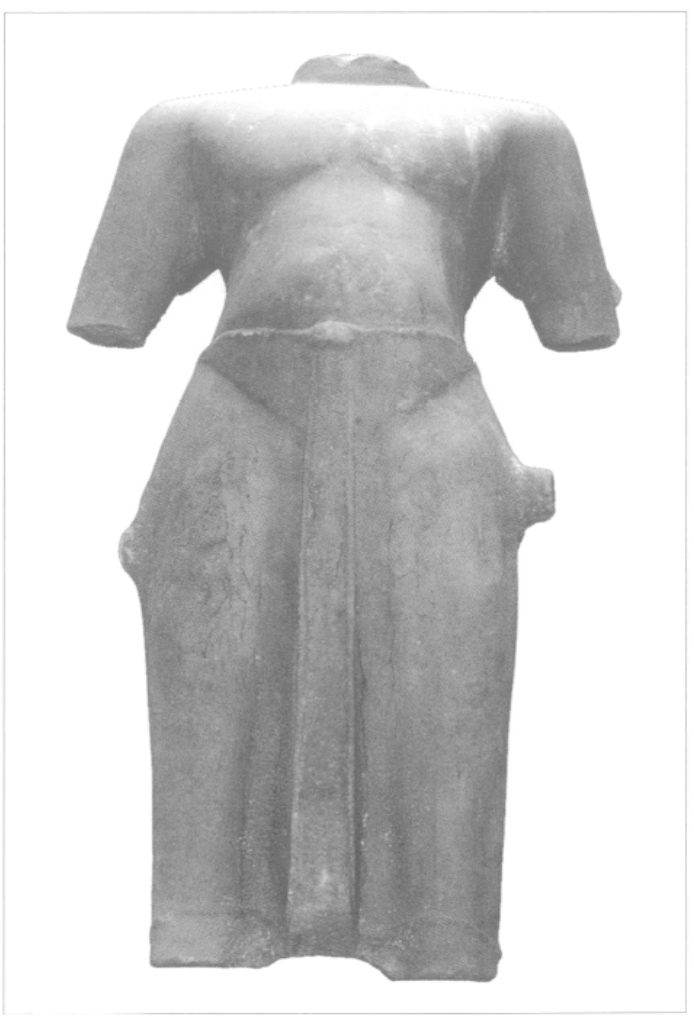

Fig. 5 : corps de Viṣnu debout (VTH 1 526).

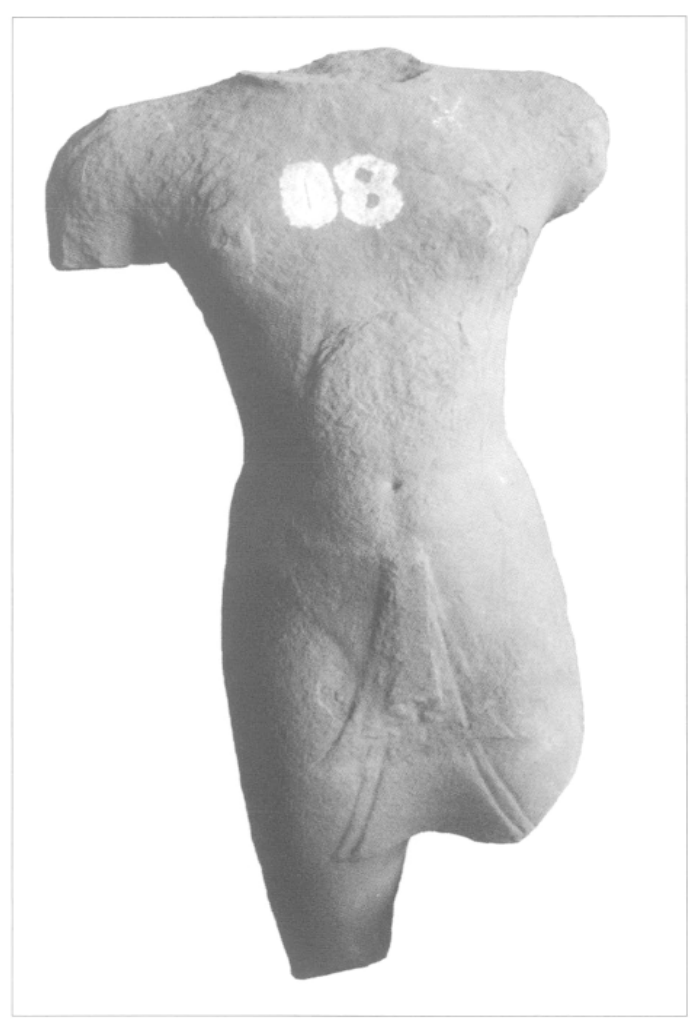

Fig. 6 : corps de Viṣnu debout (VP I 407). 


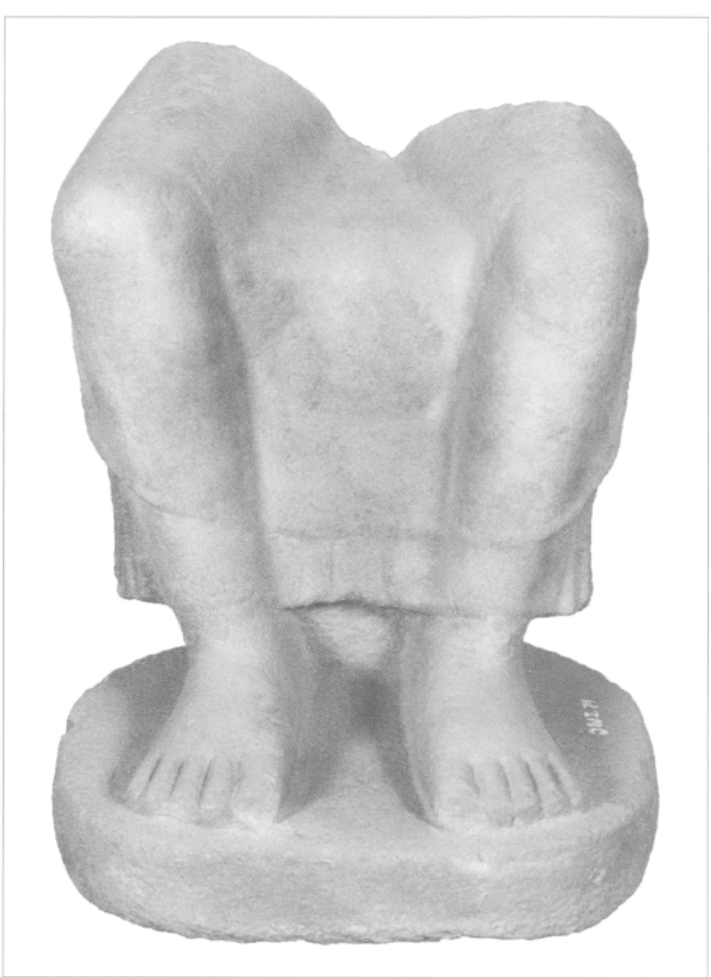

Fig. 7 : Buddha assis à l'occidentale (VP I 74).

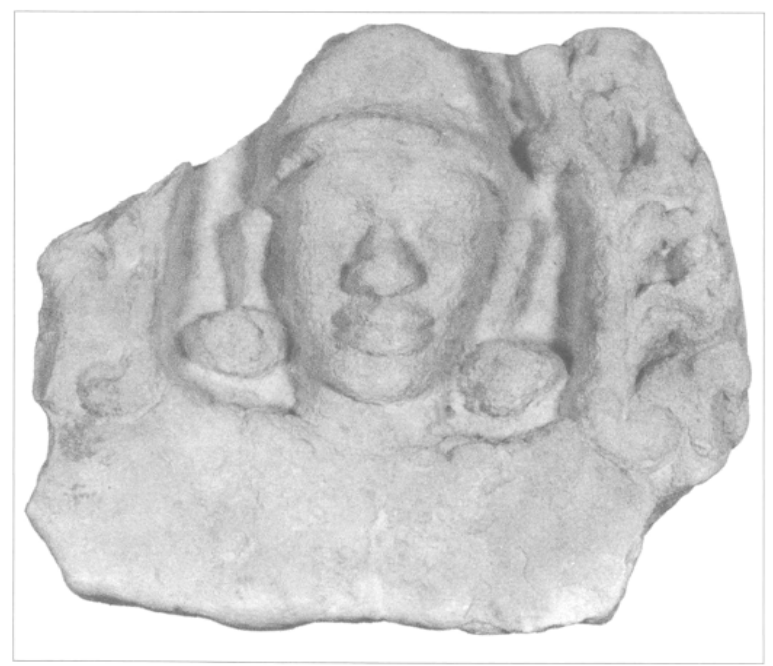

Fig. 9 : candraśālà (VP I 583).

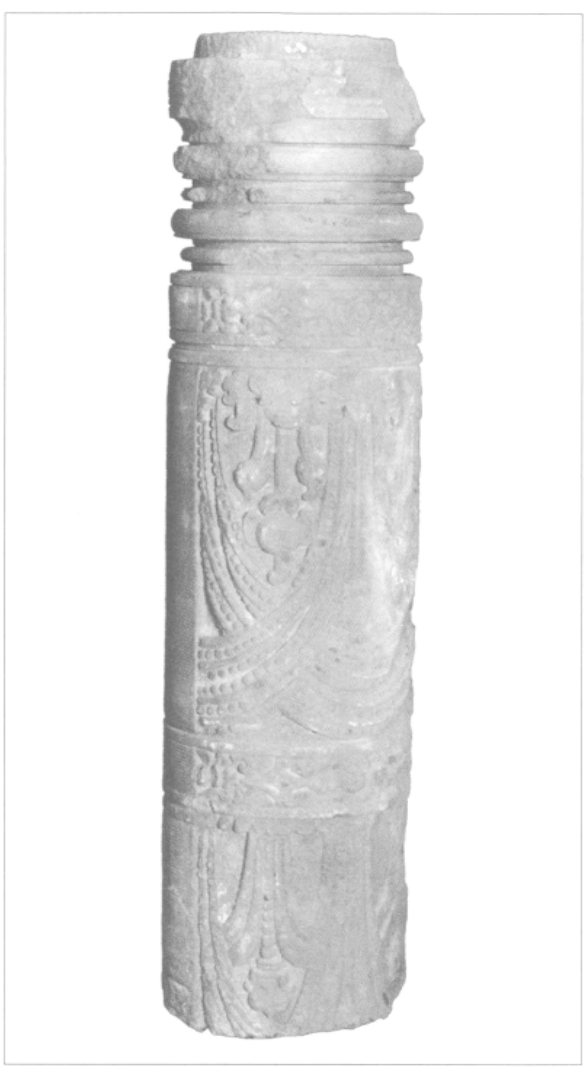

Fig. 8 : colonette préangkorienne (VP I 463).

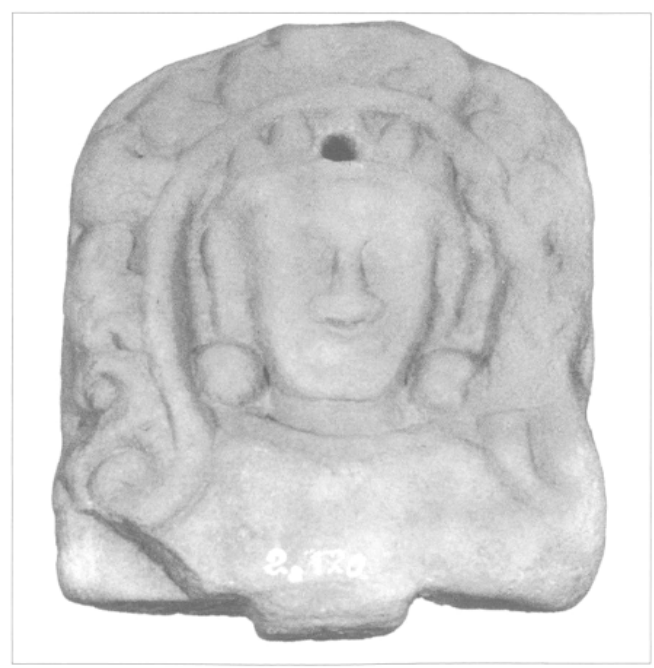

Fig. 10 : candrasiàlā (VP I 197). 


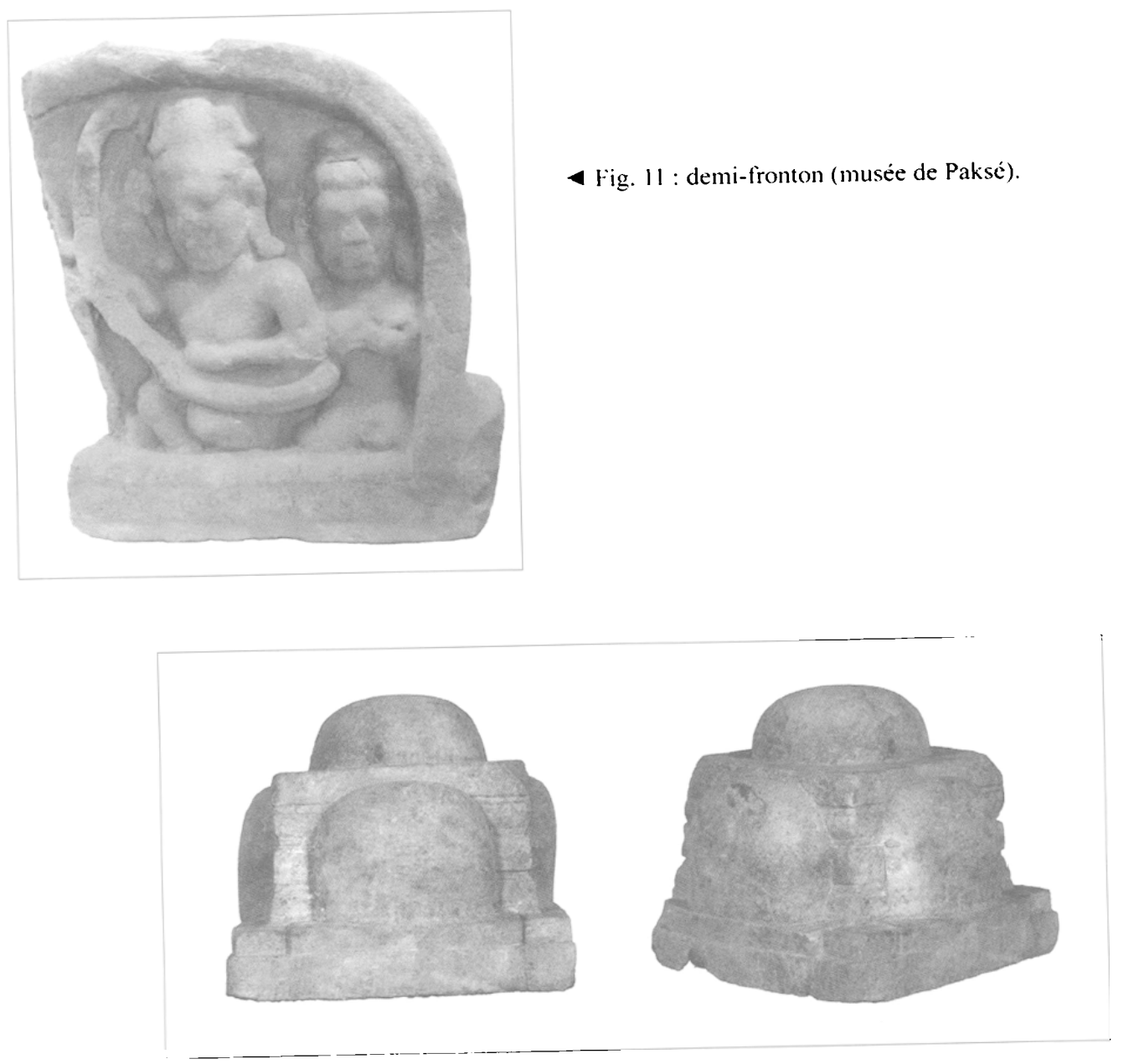

Fig. 12 : pancalinga (VP 1597 ).

- Fig. 13: Devī (VP I 485).

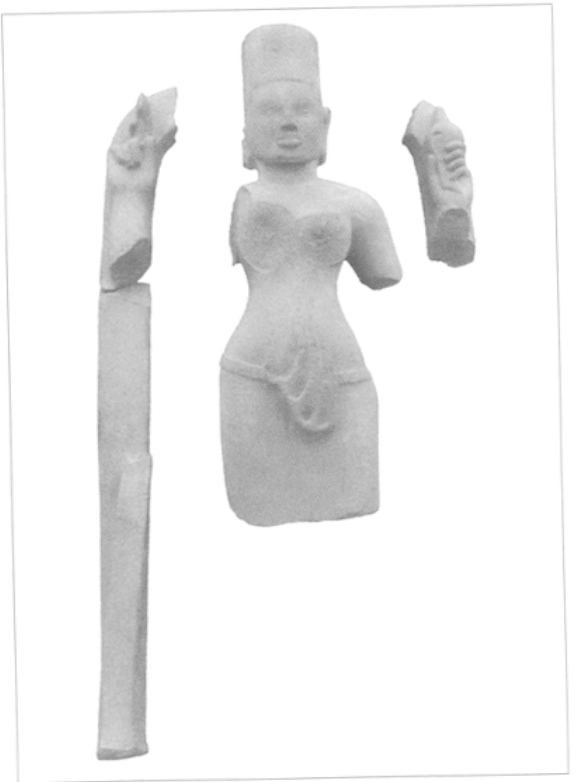




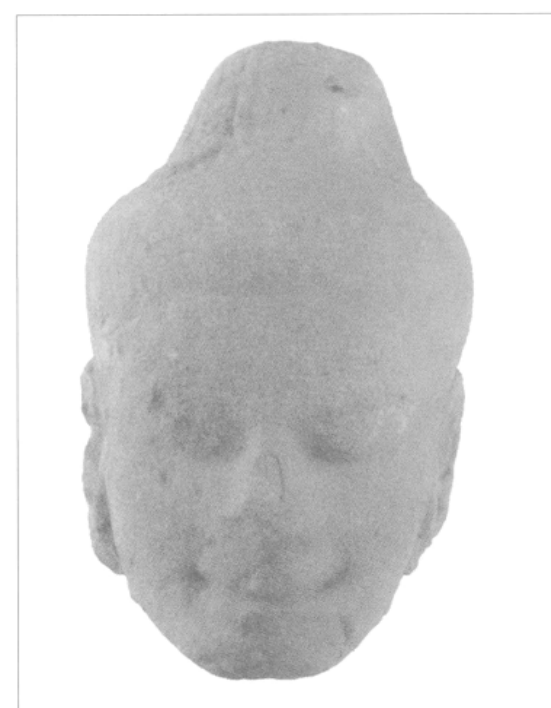

Fig. 14 : tête de divinité préangkorienne (VP I 815 ).

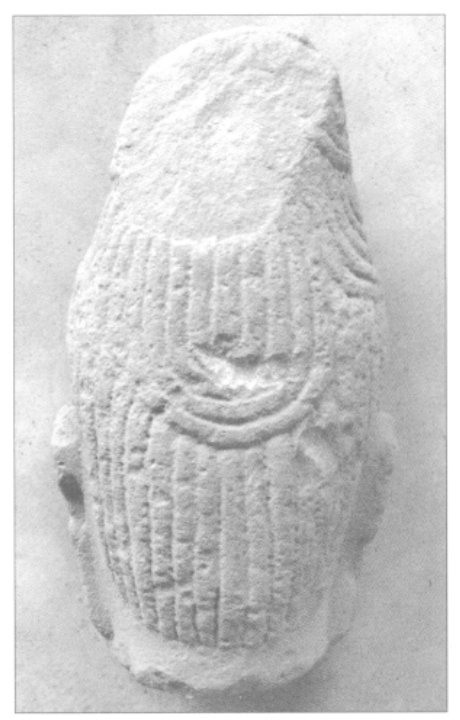

Fig. 15 : tête de divinité féminine préangkorienne (BNS I 714).

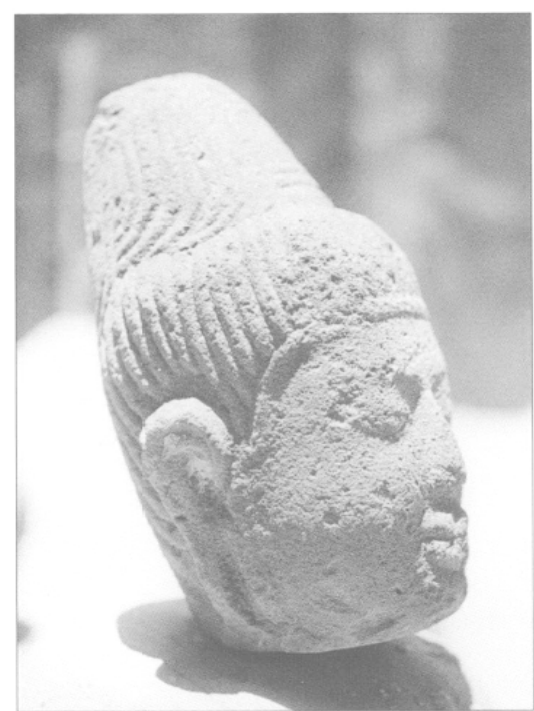

Fig. 16: tête de divinité féminine préangko:ienne (cliché EFPP 1875).

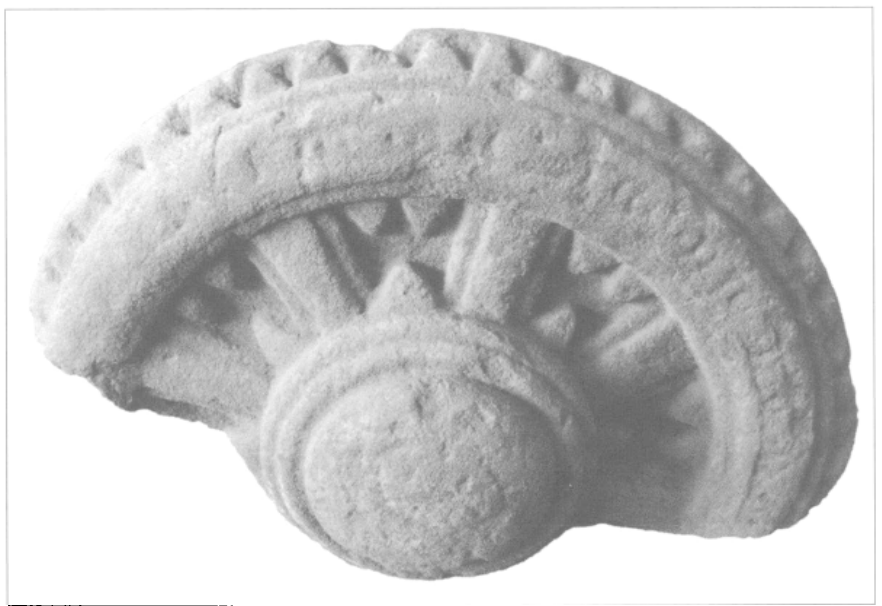

Fig. 17 : roue de la Loi (VP 1 785).

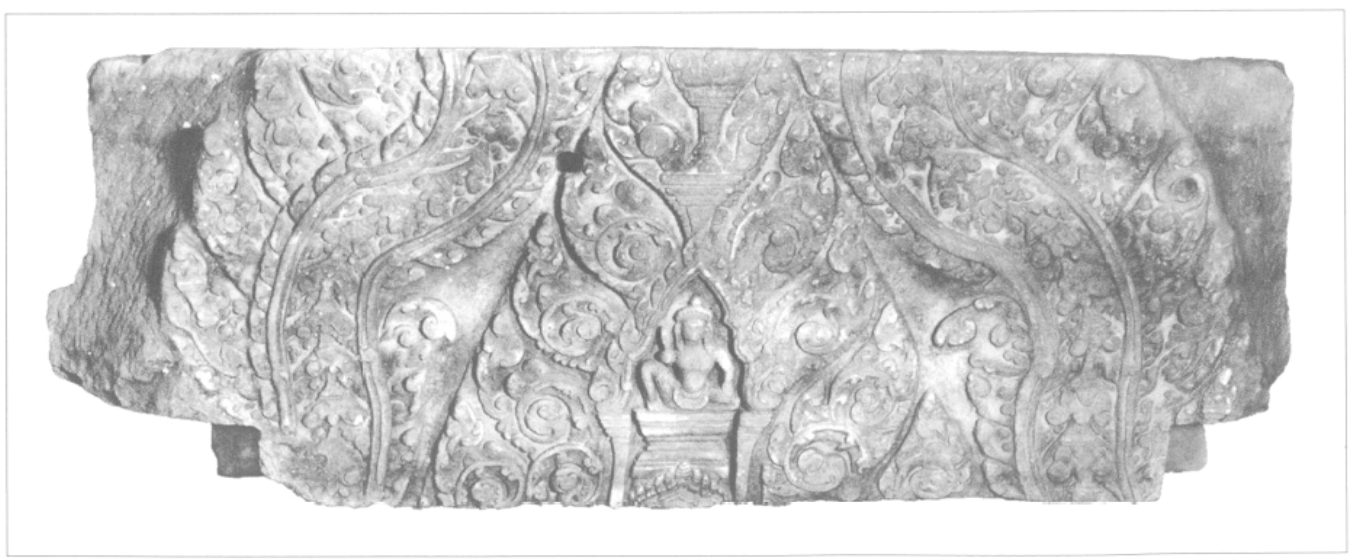

Fig. 18 : élément de fronton (VP I 128). 


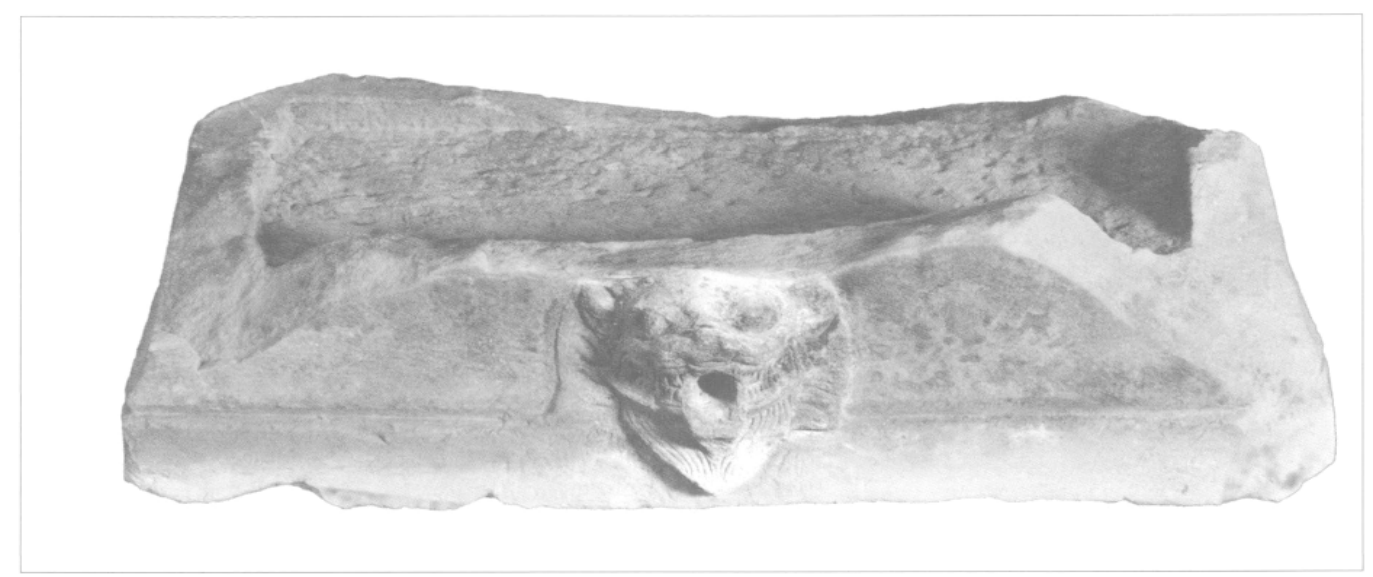

Fig. 19 : cuve de Nang Sida (HNS I 492).
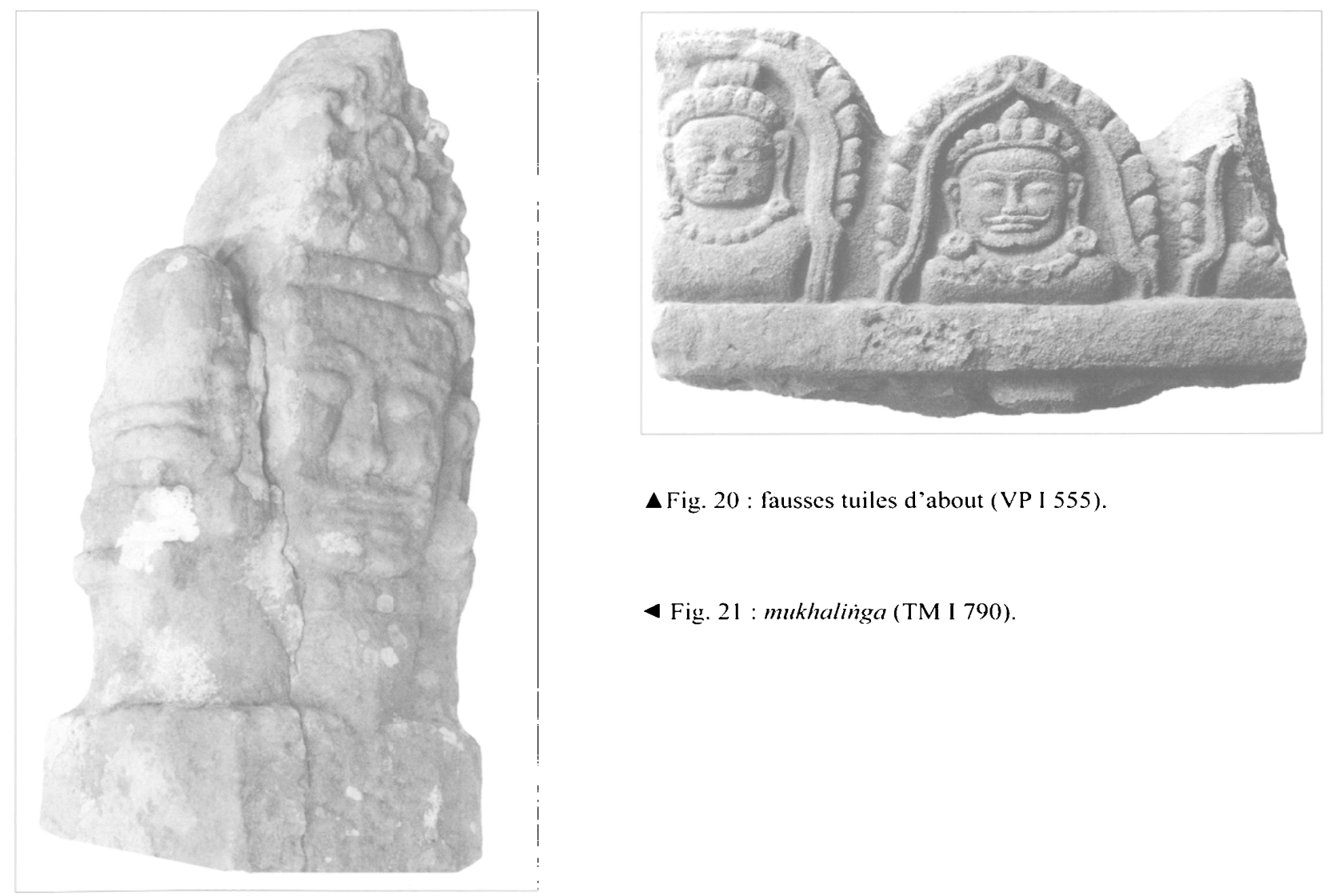

A Fig. 20 : fausses tuiles d'about (VP I 555).

4 Fig. 21: mukhalinga (TM I 790). 


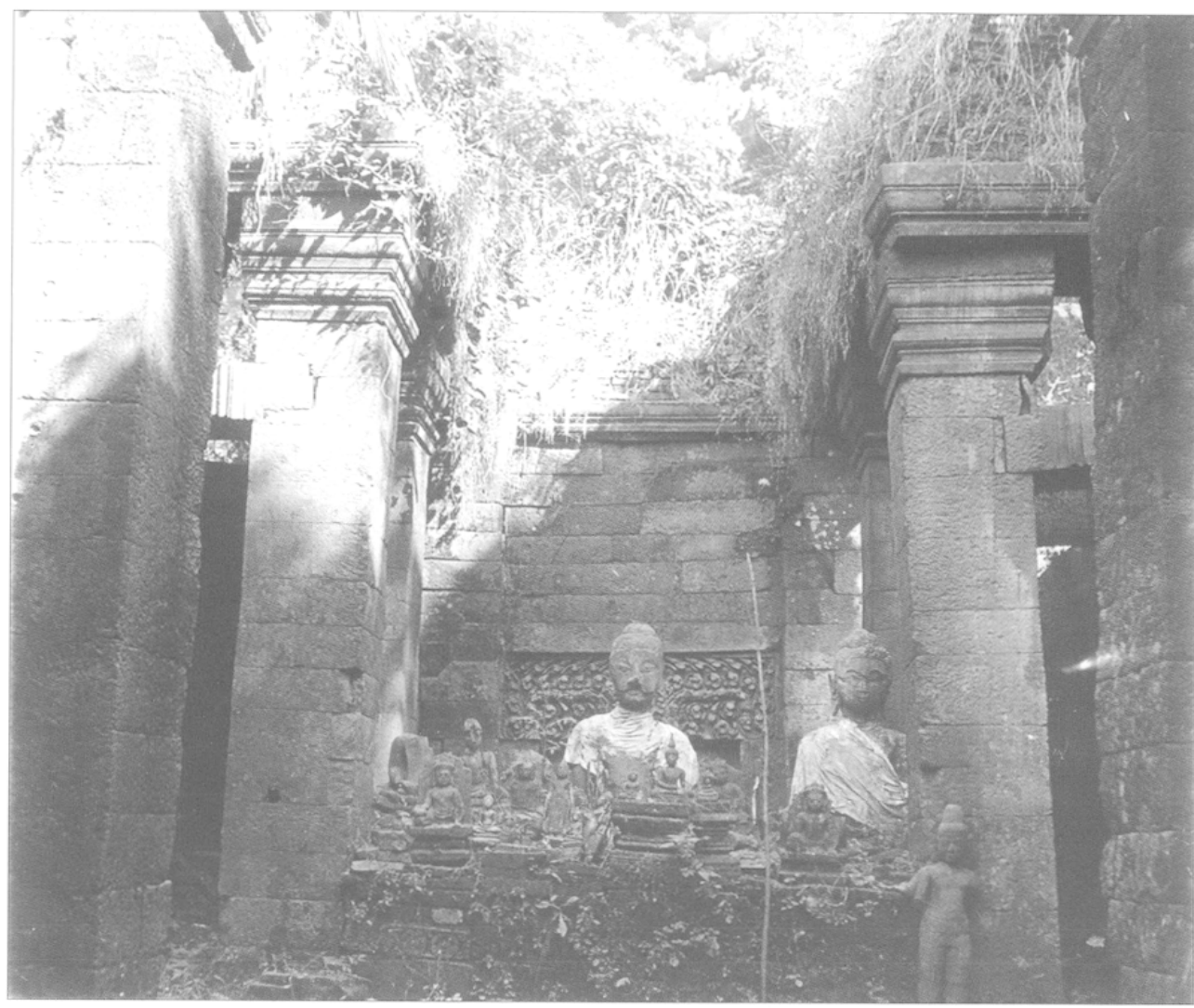

Fig. 22 : avant-corps du sanctuaire de Vat Phu (un Vișṇu angkorien - disparu - en bas à droite).
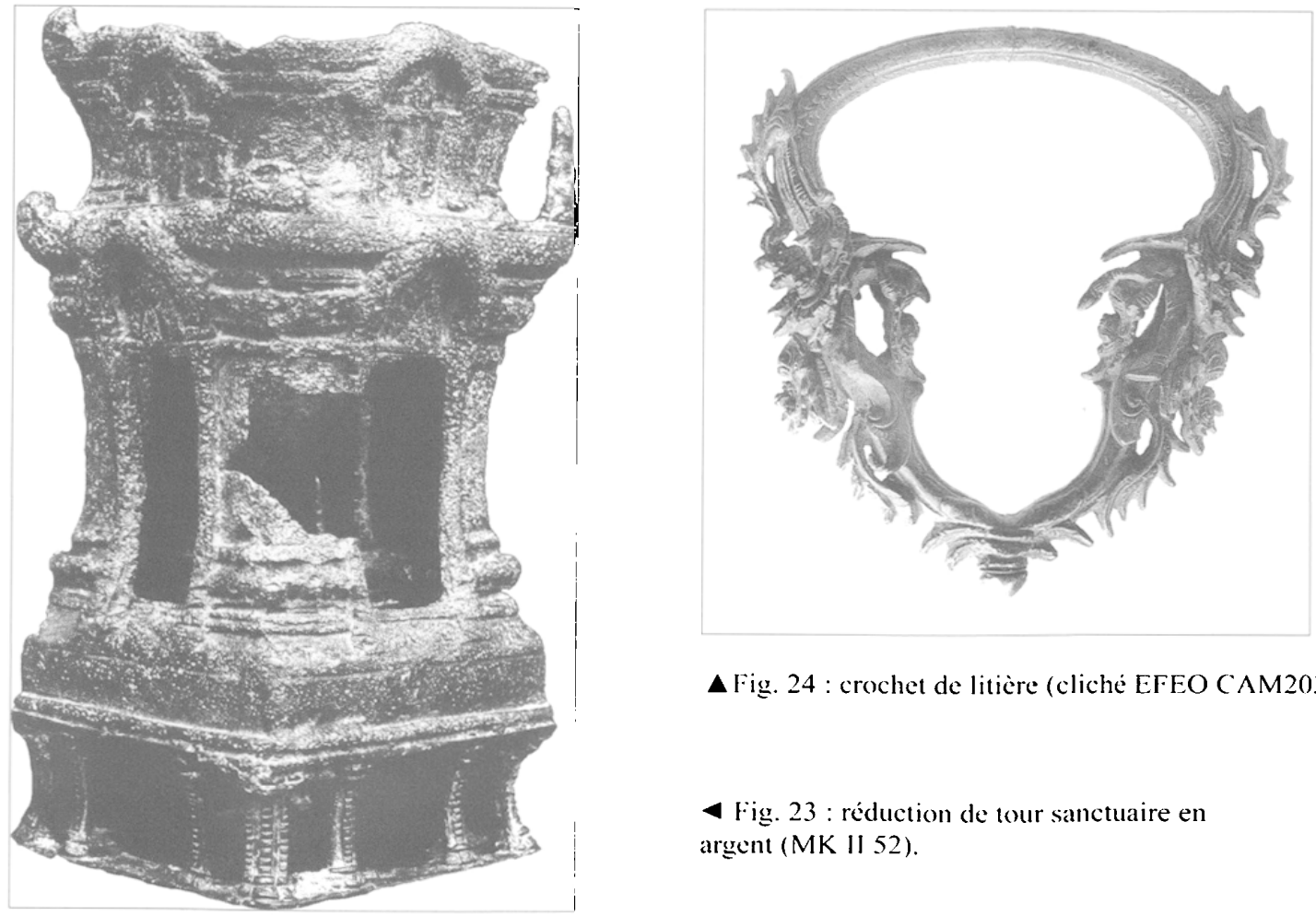

$\Delta$ Fig. 24 : crochet de litière (cliché EFEO CAM2039).

4 Fig. 23 : réduction de tour sanctuaire en argent (MK II 52). 


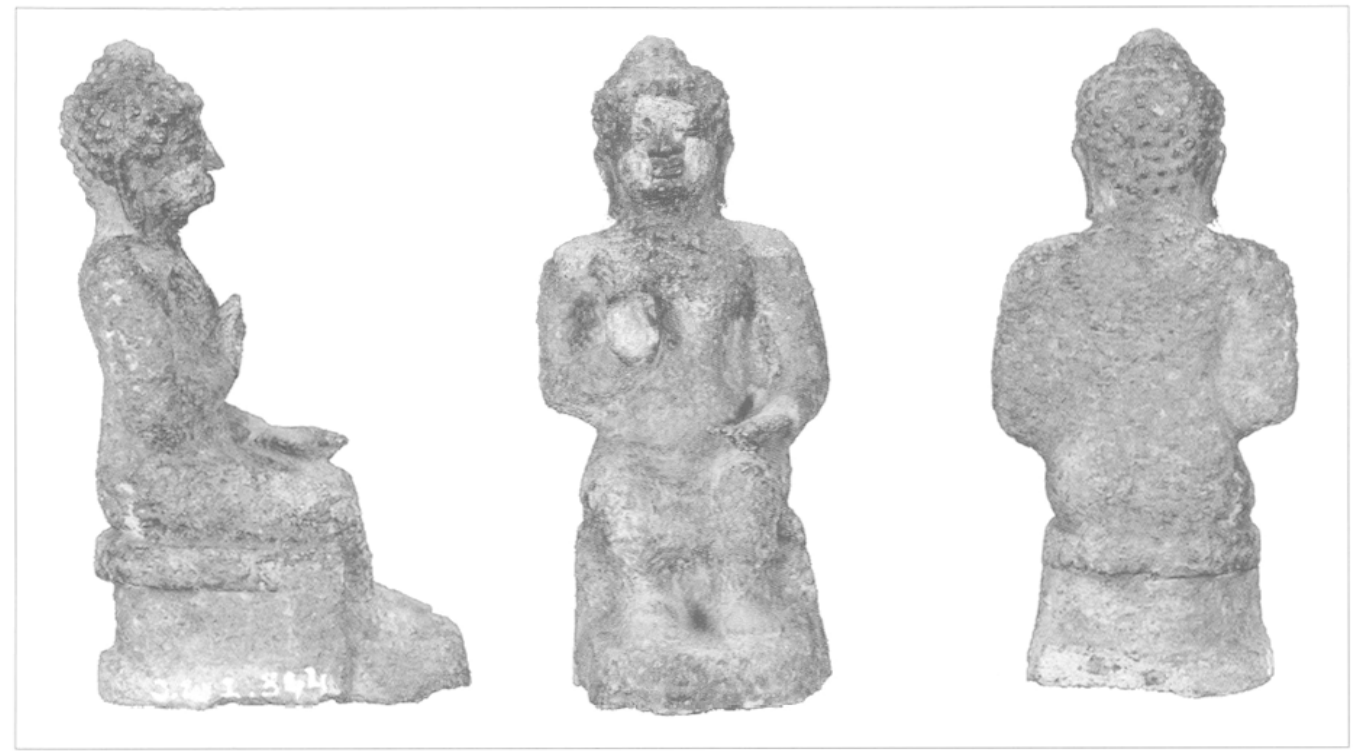

Fig. 25 : statuette de Buddha en latérite (VP I 344).

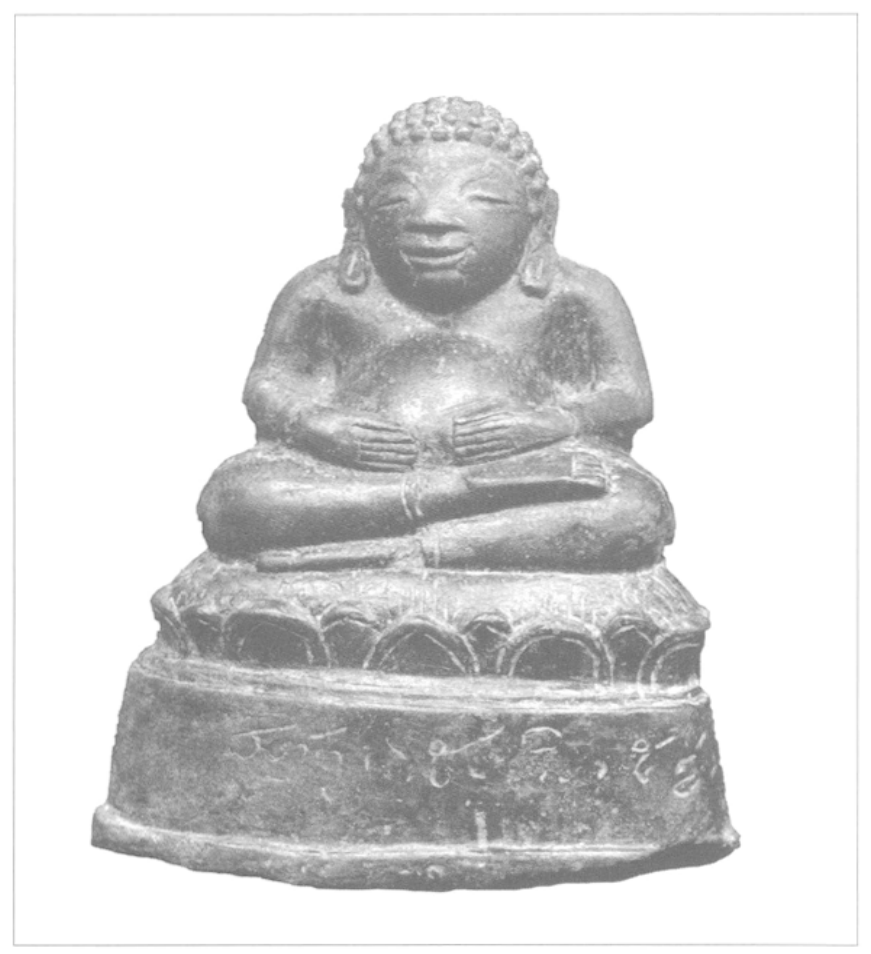

Fig. 26 : Kaccāyana (VP II 80). 


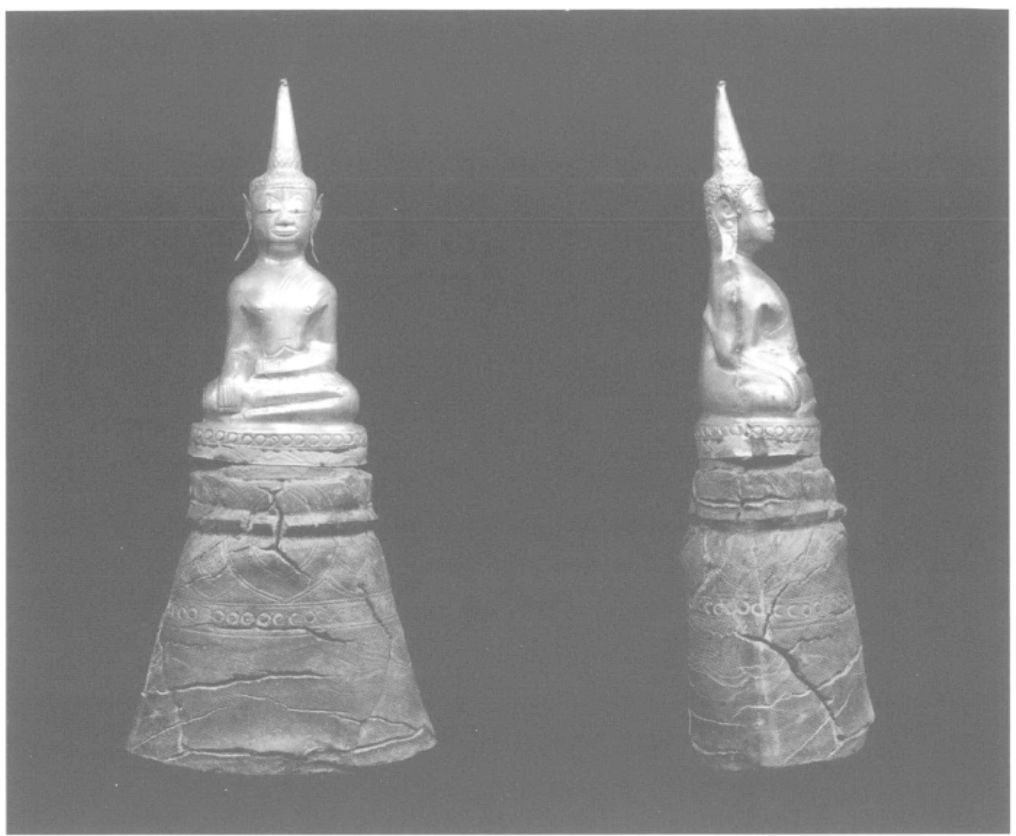

Fig. 27: Buddha en résine végétale ( $\mathrm{HSH}$ X 35).

- Fig. 28 : Avalokiteśvara (copie) (VP I 178).

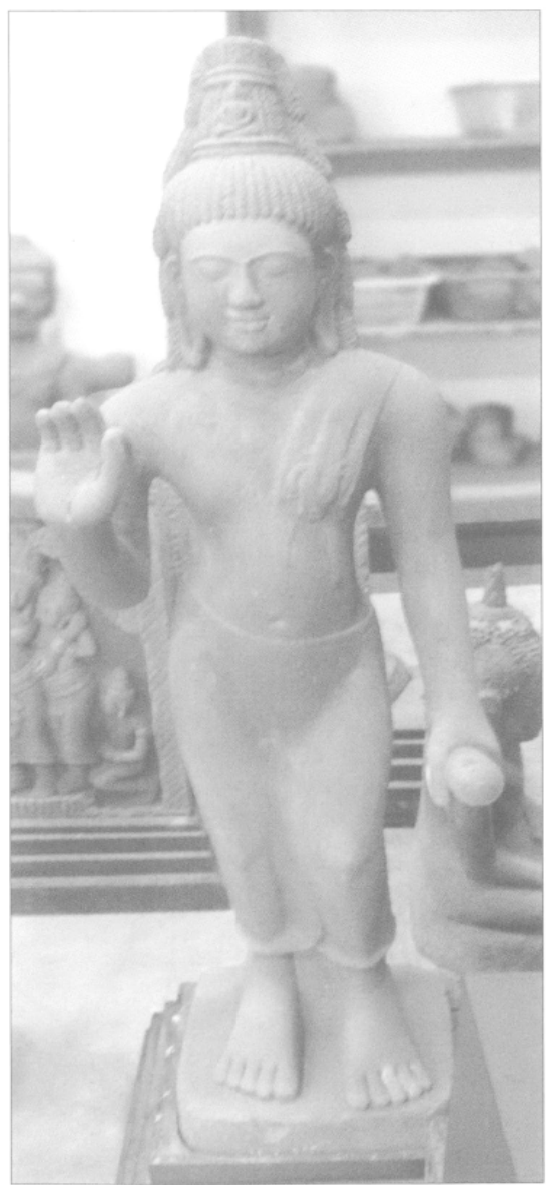

